IZA DP No. 4603

Non-unitary Models of Household Behavior:

A Survey of the Literature

Pierre-André Chiappori

Olivier Donni

November 2009

Forschungsinstitut

zur Zukunft der Arbeit

Institute for the Study

of Labor 


\title{
Non-unitary Models of Household Behavior: A Survey of the Literature
}

\author{
Pierre-André Chiappori \\ Columbia University \\ Olivier Donni \\ Université de Cergy-Pontoise \\ and IZA
}

Discussion Paper No. 4603

November 2009

\author{
IZA \\ P.O. Box 7240 \\ 53072 Bonn \\ Germany \\ Phone: +49-228-3894-0 \\ Fax: +49-228-3894-180 \\ E-mail: iza@iza.org
}

\begin{abstract}
Any opinions expressed here are those of the author(s) and not those of IZA. Research published in this series may include views on policy, but the institute itself takes no institutional policy positions.

The Institute for the Study of Labor (IZA) in Bonn is a local and virtual international research center and a place of communication between science, politics and business. IZA is an independent nonprofit organization supported by Deutsche Post Foundation. The center is associated with the University of Bonn and offers a stimulating research environment through its international network, workshops and conferences, data service, project support, research visits and doctoral program. IZA engages in (i) original and internationally competitive research in all fields of labor economics, (ii) development of policy concepts, and (iii) dissemination of research results and concepts to the interested public.
\end{abstract}

IZA Discussion Papers often represent preliminary work and are circulated to encourage discussion. Citation of such a paper should account for its provisional character. A revised version may be available directly from the author. 
IZA Discussion Paper No. 4603

November 2009

\section{ABSTRACT \\ Non-unitary Models of Household Behavior: A Survey of the Literature*}

This article considers non-unitary models of household behavior. These models suppose explicitly that households consist of a number of different members with preferences that are different from each other. They can be split up into two principal categories: cooperative (or collective) models, in which the allocations are supposed to be Pareto efficient; and noncooperative (or strategic) models which are based on the concept of Cournot-Nash equilibrium. The demand functions that describe household behavior in these models are subject to constraints that differ from the traditional Slutsky conditions. In addition, in a certain number of specific cases, the preferences of the different household members can be identified from observable behavior.

\section{NON-TECHNICAL SUMMARY}

This article presents the various approaches recently developed in economics to model the behavior of multi-person households. In these approaches, each member in the household is represented by specific, different preferences. The outcome of the decision process is then the result of a bargaining between household members. Importantly, the theoretical implications of these models differ from what is generally obtained in more traditional models of household behavior. In addition, in a certain number of specific cases, the preferences of the different household members can be identified from observable behavior.

JEL Classification: D11, D13, J22

Keywords: households, collective model, strategic model, testability, identification

Corresponding author:

Olivier Donni

THEMA

Université de Cergy-Pontoise

33 Boulevard du Port

95011 Cergy Cedex

France

E-mail: olivier.donni@eco.u-cergy.fr

\footnotetext{
* This paper is an updated translation of our paper "Les modèles non-unitaires de comportement des ménages: un survol de la literature", published in Actualité économique: revue d'analyse économique. We are conscious that this survey does not justice to the literature that has appeared in the intervening three years.
} 
Men are not, when brought together, converted into another kind of substance, with different properties.

John Stuart Mills (1965 [1843]), Collected Works, vol.8, p.879.

\section{$1 \quad$ Introduction $^{1}$}

\subsection{The Current State of Play}

In Microeconomic textbooks, household behavior, even if this household consists of several different members, is almost always analyzed using a single household utility function, which is maximized subject to a budget constraint. This 'unitary' approach, whereby individual preferences are aggregated up to some kind of social preference function, has the advantage of producing testable restrictions on household behavior, and thus to allow the rigorous empirical testing of the underlying hypotheses. For example, in the context of consumer theory, the demands for goods have to be homogeneous of degree zero, and the associated Slutsky matrix should be symmetric and negative semi-definite; moreover, demand should satisfy an 'income pooling' property, according to which only the sum of exogenous income matters for the explanation of household behavior (and not its distribution between the different household members). Moreover, if these restrictions are found to hold, household preferences can be identified via information on the complete system of household demands. Econometricians can thus analyze the effect of economic policy on the behavior and the welfare of the household. This

\footnotetext{
${ }^{1}$ The only bibliographic references presented in this Introduction are those which do not appear in the remainder of the text.
} 
explains to a large extent the success that the unitary model has experienced in the literature for a number of decades.

However, an analytical approach that does not take into account the multiplicity of decision makers in the household cannot be entirely satisfactory. From a methodological point of view, the neoclassical theory of utility was developed to describe the choices made by individuals, and not those undertaken by groups such as households. Samuelson (1956) showed that a household will act like an individual if the household members choose to maximize a social welfare function, but this result relies on several, particularly restrictive hypotheses; for instance, the presence of bargaining between members is either ruled away, or submitted to the condition that individual threat points or bargaining powers cannot depend on wages or individual incomes. Becker's $(1974,1991)$ Rotten Kid Theorem yields a conclusion similar to that of Samuelson, in the case where the household consists of one altruistic 'patriarch' and one (or more) egotistical 'kids'. This result does, however, also pose a number of problems; for instance, Bergstrom (1989) showed that preferences have to satisfy some very restrictive properties for the Rotten Kid Theorem to apply. ${ }^{2}$ From an empirical point of view, the symmetry of the Slutsky matrix has regularly been tested in this literature, either on consumption or on labor supply, and almost always rejected; furthermore, the income pooling property has equally been rejected on many occasions. Last, in addition to these fundamental criticisms, the unitary model has shown

\footnotetext{
${ }^{2}$ Another essential condition for this theorem to hold is that the altruistic household member has to have sufficient resources available in order to be able to modify her transfers as a function of the decisions taken by other household members.
} 
itself to be too restrictive for the analysis of a certain number of questions, such as intra-household inequality, economic policies which target certain household members only, or the formation and dissolution of households.

Given both the scarcity of convincing empirical support for the unitary model and its relative lack of theoretical foundations, a number of researchers have developed models that are based on a non-unitary description of household decision-making. ${ }^{3}$ These models all share a basic theoretical trait: each individual in the household has their own individual preferences. On the contrary, a variety of different mechanisms are appealed to in order to explain how decisions are actually taken within the household. On the one hand, non-cooperative (strategic) models use the Cournot-Nash equilibrium concept. Here, each individual within a household is considered to maximize their own utility, relative to their own budget constraints, taking the actions of other household members as given. One drawback of these models is that, as game theory tells us, the equilibrium outcomes are typically not Pareto efficient. As such, it is generally possible, starting from this equilibrium, to increase the welfare of one household member without reducing the welfare of any other member. On the other hand, cooperative (or collective) models are based on the hypothesis that the decision process within the household, whatever that may turn out to be, produces Pareto-efficient outcomes. This category includes, in particular, models of household behavior based on the axiomatic theory of bargaining with symmetric information (for example, the

\footnotetext{
${ }^{3}$ Alderman, Chiappori, Haddad, Hoddinott and Kanbur (1995) emphasize the importance of the question of the distribution of resources within the household in the context of developing countries, and call for the development of models which allow such questions to be taken into account.
} 
Nash and Kalai-Smorodinsky solutions).

The aim of the present survey is to summarize research carried out on non-unitary models in recent years, and to update the surveys provided by Bourguignon and Chiappori (1992), Chiappori (1997), Chiuri (2000) and Vermeulen $(2002) \cdot{ }^{4}$ In the following, we will mainly concentrate on cooperative models, insisting on their empirical content, as it is with respect to these models that the most significant theoretical advances have taken place. We will, however, not ignore other types of models. ${ }^{5}$ Section 2 introduces the concept of distribution factors and characterizes the demand functions that result from cooperative models under the most general hypotheses. Section 3 introduces the question of the identification of the structural components of the model. The question is as follows: what can we say about individual preferences and the decision process within the household when we only observe household-level demands? Section 4 presents more specific cooperative models, namely those relating to labor supply and intertemporal choice under uncertainty. This section also considers households consisting of more than two decision-makers, and the specification of threat points in bargain-

\footnotetext{
${ }^{4}$ Lundberg and Pollak (1996) and Strauss, Mwabu and Beegle (2000) also consider non-unitary models in their literature surveys, but are more particularly interested in the question of the intra-household distribution of resources.

${ }^{5}$ Nonetheless, we will not present here the approaches inspired by Feminist Economics (Folbre, 1986) or Institutional Economics (Pollak, 1985). These insist on the conflicts which can occur within the household, but in a relatively non-formalized way, and even if it is difficult to deny the interest of their subject matter, the empirical content of the models is fairly limited. We will also not consider the applications of non-unitary models to general equilibrium (Gersbach and Haller, 2001), optimal taxation (Apps and Reese, 1988, 2009;Brett, 1998) and couple formation (Becker and Murphy, 2000).
} 
ing models. Section 5 then considers a certain number of results from noncooperative models, focussing in particular on their links with cooperative models. A summary table of empirical estimates of these different models is provided in the Appendix.

\subsection{Notation and Definitions}

We consider a household consisting of two individuals, $A$ and $B$. These individuals both have distinct preferences over a set of $K$ consumption goods. In the most general models that we will present, the goods that are purchased serve one of three different uses: private consumption by $A$, private consumption by $B$, and public consumption. These different uses are denoted respectively by the following vectors:

$$
\boldsymbol{q}_{A}=\left(\begin{array}{l}
q_{A}^{1} \\
\vdots \\
q_{A}^{K}
\end{array}\right), \quad \boldsymbol{q}_{B}=\left(\begin{array}{l}
q_{B}^{1} \\
\vdots \\
q_{B}^{K}
\end{array}\right), \quad \boldsymbol{Q}=\left(\begin{array}{l}
Q^{1} \\
\vdots \\
Q^{K}
\end{array}\right)
$$

and we have that:

$$
\boldsymbol{\xi}=\boldsymbol{q}_{A}+\boldsymbol{q}_{B}+\boldsymbol{Q}
$$

where the vector $\boldsymbol{\xi}=\left(\xi^{1}, \ldots, \xi^{K}\right)^{\prime}$ designates the goods purchased by the household. The household budget constraint is linear and is given by

$$
\boldsymbol{\pi}^{\prime} \cdot \boldsymbol{\xi}=y
$$

where $y$ refers to total household spending (including when appropriate spending on leisure) and $\boldsymbol{\pi}=\left(\pi^{1}, \ldots, \pi^{K}\right)^{\prime}$ is the price vector corresponding to $\boldsymbol{\xi}$. 
A number of remarks can usefully be made at this point. First, some goods may combine aspects of private and public consumption. For example, "telephone services" consist of the (public) subscription and the minutes of conversation or other services that are used (privately) by each individual. Next, in the context of a labor-supply model, the vector $\boldsymbol{\xi}$ may include the leisure of household members. This latter is typically analyzed as a private consumption, but may also include externality aspects on the well-being of the individual's partner. Last, the econometrician does not observe in general the use that is made of the different goods that households purchase, and only has information on the total demand vector $\boldsymbol{\xi}$. As such, any theory of household behavior, if it is to be of use to econometricians, should predict behavior based only on the observation of this vector. ${ }^{6}$

In the most general case, we imagine that an individual's preferences depend not only on their own consumption, but also on that of their partner. This situation includes certain very general forms of altruism, but also externalities in consumption. In this case, the utility functions of household members have the following form: ${ }^{7}$

$$
U_{i}\left(\boldsymbol{q}_{A}, \boldsymbol{q}_{B}, \boldsymbol{Q}\right)
$$

where $U_{i}(\cdot)$ has the usual properties of continuity, positive monotonicity and concavity. Under this hypothesis, any distinction between public and

\footnotetext{
${ }^{6}$ The econometrician may sometimes be able to obtain information on the private and public components of a good. If information is also available, with respect to the private component of the good, which part is consumed by $A$ and which by $B$, the good is called "assignable". This situation is, however, exceptional.

${ }^{7}$ In the remainder of the text, the index $i$ will refer indiscriminately to agent $A$ or $B$.
} 
private consumption is purely artificial. For some applications, however, it will be necessary to introduce stronger hypotheses regarding preferences. For example, if agents are egotistical, and in the absence of externalities, individual preferences can be written as

$$
U_{i}\left(\boldsymbol{q}_{i}, \boldsymbol{Q}\right)
$$

An intermediary situation between the types described by (2) and (3) comes from altruistic (caring) agents, in Becker's sense, in an environment without externalities. Preferences can then be written as:

$$
U_{i}\left(u_{A}\left(\boldsymbol{q}_{A}, \boldsymbol{Q}\right), u_{B}\left(\boldsymbol{q}_{B}, \boldsymbol{Q}\right)\right) .
$$

This definition is close to the notion of pure altruism that is found in the economic literature on the subject.

A number of the distinctions that we can make refer to the nature of the goods rather than to individuals' preferences. Consider, for example, some good $k$. In the case without externalities, we can imagine the following situations:

(a) good $k$ is (purely) private if $Q^{k}=0$;

(b) good $k$ is (purely) public if $\left(q_{A}^{k}+q_{B}^{k}\right)=0$.

In what follows, we will sometimes consider the specific cases where either all goods are private or all goods are public. ${ }^{8}$ We will also examine the case where each good is either purely private or purely public. If we let

\footnotetext{
${ }^{8}$ Note that, if all goods are public, the distinction between altruistic and egotistical agents disappears.
} 
$\boldsymbol{q}=\boldsymbol{q}_{A}+\boldsymbol{q}_{B}$ denote the household's demand for private goods, then this formally means that

$$
\boldsymbol{Q} \odot \boldsymbol{q}=\mathbf{0},
$$

where $\odot$ is the Hadamard product (i.e., the element-by-element product). In this case, we say that the public and private goods are disjoint, and we designate the prices of private and public goods respectively by the vectors $\boldsymbol{p}$ and $\boldsymbol{P}$. For reasons which will become clear below, the vector $\boldsymbol{p}$ is of dimension $K$ and contains zeros instead of prices for public goods. The vector $\boldsymbol{P}$ is defined similarly, so that we have $\boldsymbol{\pi}=\boldsymbol{p}+\boldsymbol{P}$.

If some good is consumed by one person only in the household, the distinction between public and private good loses its meaning, and, in this case, we prefer to talk about exclusive goods. Note that this property of exclusivity is more a characteristic of preferences than of the good itself. For example, cigarettes are generally considered as a private good (if we exclude any resulting externalities), but if one of the household members does not smoke, then cigarettes will be classified as an exclusive good. These types of goods are often encountered by the econometrician in household survey data on consumption. A typical example, which is often given, is that of clothing when this is sexually differentiated. Another example, which is more debatable, is that of the leisure of different household members.

The presence of exclusive goods in the household is often necessary for us to be able to understand the mechanisms which determine the allocation of resources. This aspect will be made clearer in the remainder of the article, but we can note at this preliminary stage that the quantity of an exclusive good consumed by an individual is a guide as to the distribution of decision 
power in the household. The intuition, if exclusive goods are superior, is that their consumption will be greater as the decision power of the person to whom that good is associated is larger.

\section{Cooperative Models - General Theory}

\subsection{The Demand for Goods}

As we noted in the Introduction, cooperative models are based on the sole hypothesis that the household decision process leads to Pareto-efficient outcomes. However, the actual process which determines the household's equilibrium outcome on the efficiency frontier is not necessarily specified. In principle, this process could be a function of any kind of variable which reflects the household environment. Some of these variables, called "distribution factors", play a particularly important role as they will affect the decision process within the household without affecting preferences or the budget constraint. ${ }^{9}$ Numerous examples of such variables can be found in Household Economics and Development Economics. For example, Lundberg, Pollak and Wales (1997) analyze the effects on the structure of consumption of a change, in the United Kingdom in the 1970s, in the beneficiary of child support. They notably demonstrate that this change in recipient had an effect on the demand for children's clothing. ${ }^{10}$ Along the same lines, Thomas,

\footnotetext{
${ }^{9}$ Distribution factors are similar to the extra-environmental parameters (EEPs) in the terminology of McElroy (1990, 1997).

${ }^{10} \mathrm{~A}$ number of other contributions have confirmed this type of result by showing, in the context of testing the income-pooling condition, that the share of each individual in total exogenous income affects households' decisions. A non-exhaustive list of this kind of work
} 
Contreras and Frankenberg (2004) appeal to Indonesian data to underline that the distribution of income at the time of marriage has an impact on the subsequent health of the children. In addition, Rubalcava and Thomas (2005) show that changes in the amount of support to single women with children (AFDC) in the USA has an effect on the consumption and labor supply of couples with children. Duflo (2000) has derived related conclusions from a careful analysis of a reform of the South African social pension program that extended the benefits to a large, previously not covered black population. She finds that the recipient's gender - a typical distribution factor - is of considerable importance for the consequences of the transfers on children's health. The analysis in Chiappori, Fortin and Lacroix (2002), inspired by the work of Becker (1991), considers marriage market indicators and marriage legislation in the USA. They find that these variables influence the labor supply of American households. ${ }^{11}$ Equally, Orefficce (2007) analyzes the effect of the legalization of abortion on the labor supply of American households. Last, Folbre (1997) provides numerous additional examples based on certain legislative aspects (the right of women to possess land, to participate in the labor market, to be protected against domestic violence, etc).

Suppose that agents' preferences have the general form (2) and that the includes Behrman (1988), Thomas (1990, 1992, 1994), Schultz (1990), Phipps and Burton (1992), Haddad and Hoddinott (1994), Duflo (2000), Kooreman (2000), and Lechene and Attanassio (2002). In particular, Altonji, Hayashi and Kotlikoff (1992) consider the cadre of the extended family, while Klassen (1998) and Moehling (2005) appeal to historical data.

${ }^{11}$ Similar conclusions are reached with different data by Gray (1998), Moreau and Donni (2002) and Grossbard-Schechtman and Neuman (2003). 
$J$ distribution factors which are pertinent for the problem at hand are designated by $s=\left(s_{1}, \ldots, s_{J}\right)^{\prime}$. In an attractive representation, the Pareto-efficient solution can be obtained from the maximization of a utilitarian social welfare function with appropriate weights. ${ }^{12}$ This thus implies that there exists a function $\mu(y, \boldsymbol{\pi}, \boldsymbol{s}) \in[0,1]$ such that the household choice is described by the programme below:

$$
\max _{\boldsymbol{q}_{A}, \boldsymbol{q}_{B}, \boldsymbol{Q}} \mu(y, \boldsymbol{\pi}, \boldsymbol{s}) \cdot U_{A}\left(\boldsymbol{q}_{A}, \boldsymbol{q}_{B}, \boldsymbol{Q}\right)+(1-\mu(y, \boldsymbol{\pi}, \boldsymbol{s})) \cdot U_{B}\left(\boldsymbol{q}_{A}, \boldsymbol{q}_{B}, \boldsymbol{Q}\right)
$$

subject to constraint (1). The function $\mu(y, \boldsymbol{\pi}, \boldsymbol{s})$ can be interpreted as an index of the distribution of power within the household. If $\mu=0$, the preferences of $B$ are imposed dictatorially in the household, and $A$ has no decisionmaking power. If, on the contrary, $\mu=1$, it is $A$ 's preferences which are imposed. We imagine that in general $\mu(y, \pi, s)$ is a continuous function (and differentiable to boot) and homogeneous of degree zero in $y$ and $\boldsymbol{\pi}$.

As we can see, the cooperative approach is characterized by the maximization of a function. Even so, and contrary to the unitary case, this function cannot be interpreted as a traditional utility function as it depends on income, prices, and the distribution factors. ${ }^{13}$ The demands that result from the programme (5) will not in general exhibit the habitual properties of Marshallian demand functions (Pollak, 1977). However, it can be noted that

\footnotetext{
${ }^{12}$ More generally, any Pareto efficient solution can be obtained as the solution of an optimization problem such as

$$
\max _{\boldsymbol{q}_{A}, \boldsymbol{q}_{B}, \boldsymbol{Q}} W\left[U_{A}\left(\boldsymbol{q}_{A}, \boldsymbol{q}_{B}, \boldsymbol{Q}\right), U_{B}\left(\boldsymbol{q}_{A}, \boldsymbol{q}_{B}, \boldsymbol{Q}\right), y, \boldsymbol{\pi}, \boldsymbol{s}\right]
$$

subject to constraint (1), where $W(\cdot)$ is a function increasing in its first two arguments.

${ }^{13}$ See Browning, Chiappori and Lechène 2006 for a detailed discussion.
} 
if the function $\mu$ is fixed, then programme (5) boils down to the maximization of a utility function. This implies, in other words, that household demands can be written as follows:

$$
\begin{aligned}
\boldsymbol{q}_{i} & =\boldsymbol{q}_{i}(\boldsymbol{\pi}, y, \mu(y, \boldsymbol{\pi}, \boldsymbol{s})) \\
\boldsymbol{Q} & =\boldsymbol{Q}(\boldsymbol{\pi}, y, \mu(y, \boldsymbol{\pi}, \boldsymbol{s}))
\end{aligned}
$$

where the $\boldsymbol{q}_{i}(\cdot, \mu)$ and $\boldsymbol{Q}(\cdot, \mu)$ functions satisfy the Slutsky conditions for a fixed level of $\mu$. In addition, in accordance with Hicks' aggregation theorem, the aggregated demands, defined by

$$
\begin{aligned}
\boldsymbol{\xi} & =\sum_{i=A, B} \boldsymbol{q}_{i}(\boldsymbol{\pi}, y, \mu(y, \boldsymbol{\pi}, \boldsymbol{s}))+\boldsymbol{Q}(\boldsymbol{\pi}, y, \mu(y, \boldsymbol{\pi}, \boldsymbol{s})) \\
& =\boldsymbol{\xi}(\boldsymbol{\pi}, y, \mu(y, \boldsymbol{\pi}, \boldsymbol{s}))
\end{aligned}
$$

will also satisfy the Slutsky conditions for a fixed value of $\mu$. Last, note that the distribution factors $s$ influence household choices uniquely via the $\mu$ function.

Household demands thus naturally exhibit certain characteristic properties. In addition to the trivial property of homogeneity of degree zero, we can also single out the conditions of $\mathrm{SR}(1)$, linearity and proportionality. Further, under additional hypotheses over preferences or goods, household demands will also satisfy more restrictive conditions. 


\subsection{The Characterization of Household Demands ${ }^{14}$}

\subsubsection{The Symmetric Negative plus Rank 1 or SNR(1) Condition}

We define, analogously to the model of the consumer in the unitary case, the Pseudo-Slutsky matrix as follows:

$$
\mathbf{S}=\frac{\partial \boldsymbol{\xi}}{\partial \boldsymbol{\pi}^{\prime}}+\frac{\partial \boldsymbol{\xi}}{\partial y} \cdot \boldsymbol{\xi}^{\prime}
$$

Browning and Chiappori (1998) then show that the household demands that are compatible with problem (5) have to satisfy the following restriction:

$$
\mathbf{S}=\mathbf{\Sigma}+\mathbf{R}
$$

where $\boldsymbol{\Sigma}$ is a negative symmetric semi-definite matrix and $\mathbf{R}$ is a matrix of rank 1. This equation can be interpreted geometrically if we note that, for any pair of utility functions: (a) the budget constraint determines the Pareto frontier, as a function of prices and income; and (b) the value of $\mu$ determines the location of the point that will be chosen by the household along that frontier. Consequently, any change in prices or income will displace the Pareto frontier. This displacement will lead to a change in household demands in the way described by $\Sigma$. However, the value of $\mu$ will change at the same time. This second effect, which is restricted to movements along the Pareto frontier, is defined by the matrix $\mathbf{R}$. In fact, the $\operatorname{SNR}(1)$ condition is restrictive for household demands which satisfy the homogeneity and adding-up conditions as long as the number of goods $K$ is greater or equal to $3 .{ }^{15}$ Chi-

\footnotetext{
${ }^{14}$ In what follows, we only consider local restrictions. The reader is referred to Cherchye, De Rock and Vermeulen (2007) and Cherchye and Vermeulen (2008) for global analysis.

${ }^{15}$ Three goods are sufficient for negativeness to be restrictive, while five are needed for symmetry.
} 
appori and Ekeland (2006) show, in the case where there are no distribution factors, that this condition is also locally sufficient. In other words, for any system of demands which satisfies the condition (7) in the neighborhood of some vector $\left(\boldsymbol{\pi}_{*}^{\prime}, y_{*}\right)$, there exists at least one pair of utility functions and a function $\mu$ such that the demand system is the solution to programme (5) in the neighborhood under consideration. ${ }^{16}$

A specific procedure needs to be followed for empirical tests to be carried out. The principle of this procedure is based on the fact that the matrix $\mathbf{S}$ will be $\operatorname{SNR}(1)$ if and only if the antisymmetric matrix $\left(\mathbf{S}-\mathbf{S}^{\prime}\right)$ is of rank 2 at most. The procedure is then to estimate a system of demands, to calculate the matrix $\left(\mathbf{S}-\mathbf{S}^{\prime}\right)$, and to test the rank of this matrix by appealing to existing techniques; see Robin and Smith (2000) for example. This test was carried out on Canadian data by Browning and Chiappori (1998). A system of demands for seven goods was estimated on a sample of couples without children, to show that the traditional condition of symmetry is rejected, while that of SR1 is not. Moreover, as the condition of symmetry is not rejected for single people, it would seem that not taking the multiplicity of decision makers into account in the household could explain the empirical rejection of unitary models.

\footnotetext{
${ }^{16}$ Chiappori and Ekeland (2006) also consider the implications of more restrictive hypotheses over goods, such as goods being only private, only public, or where all goods are disjoint. They show, perhaps surprisingly, that the SR(1) condition remains sufficient.
} 


\subsubsection{The Conditions of Colinearity and Proportionality}

Additional restrictions come into play as soon as we introduce distribution factors. In the first instance, consider that there is only one distribution factor, s. Browning and Chiappori (1998) then show that there exists a vector $\boldsymbol{u}$ such that:

$$
\frac{\partial \boldsymbol{\xi}}{\partial s}=\left(\mathbf{S}-\mathbf{S}^{\prime}\right) \cdot \boldsymbol{u} .
$$

This is a restrictive condition due to the fact that, as discussed above, the matrix $\mathbf{S}-\mathbf{S}^{\prime}$ is of rank 2 at most. We thus obtain a surprising result, where the effect of a distribution factor on demand is colinear to the effect of prices.

When there are at least two distribution factors, the demands have to satisfy an additional property that is particularly useful as it can be tested using cross-section data and does not require price effects to be evaluated. This property reflects the fact that distribution factors influence the demand for goods only via the function $\mu$. More precisely,

$$
\frac{\partial \boldsymbol{\xi}}{\partial s_{j}}=\theta_{j} \cdot \frac{\partial \boldsymbol{\xi}}{\partial s_{1}} \text { for all } j,
$$

where $\theta_{j}=\left(\partial \mu / \partial s_{1}\right) /\left(\partial \mu / \partial s_{j}\right)$ is a scalar. In other words, the vectors

of response of demands to a change in the various distribution factors are colinear. Equivalently, we must have that:

$$
\frac{\partial \boldsymbol{\xi}_{i} / \partial s_{j}}{\partial \boldsymbol{\xi}_{i} / \partial s_{k}}=\frac{\partial \boldsymbol{\xi}_{i^{\prime}} / \partial s_{j}}{\partial \boldsymbol{\xi}_{i^{\prime}} / \partial s_{k}} \text { for all } i, i^{\prime}
$$

This proportionality condition has now been tested in a wide variety of settings. We present only two examples. Bourguignon, Browning, Chiappori and Lechene (1993) estimate a system of six demand equations using French 
data, retaining the share of female and male labor earnings in total household income as distribution factors. Thomas and Chen (1994) appeal to the same distribution factors in their estimation of a system of ten demand equations in Taiwanese data. In both of these pieces of work, and more remarkably in the majority of empirical work, the proportionality condition is not rejected.

\subsubsection{Particular Conditions}

The restrictions discussed above are general in the sense that they result only from the hypothesis of Pareto efficiency. However, more restrictive conditions result from the adoption of particular hypotheses regarding goods or preferences.

For reasons that will become clear in the following section, the cases of preferences that are given by a utility function such as (3) and where the goods, public or private, are disjoint has been the subject of particular interest in the profession. Under these hypotheses, Chiappori (1992), and numerous other authors since, showed that the household decision process can be composed into two stages. First, the household members agree on the consumption of public goods, and on the sharing of the sum to be spent on private goods. They then each maximize independently their utilities taking into account the level of public goods and their own personal budget constraint. Formally, this implies that there exist a pair of functions, $\rho_{A}$ and $\rho_{B}$, such that $\rho_{A}+\rho_{B}=y^{*}$, where $y^{*}=y-\boldsymbol{P}^{\prime} \boldsymbol{Q}$ is household spending on private goods, such that the demand for private goods of individual $i, \boldsymbol{q}_{i}$, is given by the solution to

$$
\max _{\boldsymbol{q}_{i}} U_{i}\left(\boldsymbol{q}_{i}, \boldsymbol{Q}\right) \text { such that } \boldsymbol{p}^{\prime} \boldsymbol{q}_{i}=\rho_{i}
$$


The functions, $\rho_{A}$ and $\rho_{B}$, describe the distribution of power in the household (for a given level of public goods) and depend on the variables $y, \boldsymbol{p}, \boldsymbol{Q}$ and $\boldsymbol{s}$. Consequently, the demands for private goods can be written as:

$$
\boldsymbol{q}=\boldsymbol{q}_{A}(\boldsymbol{p}, \boldsymbol{Q}, \rho(y, \boldsymbol{p}, \boldsymbol{Q}, \boldsymbol{s}))+\boldsymbol{q}_{B}\left(\boldsymbol{p}, \boldsymbol{Q}, y^{*}-\rho(y, \boldsymbol{p}, \boldsymbol{Q}, \boldsymbol{s})\right),
$$

where $\rho=\rho_{A}$ and $y^{*}-\rho=\rho_{B}$, and where the functions $\boldsymbol{q}_{A}(\cdot)$ and $\boldsymbol{q}_{B}(\cdot)$ are Marshallian demands conditional on $\boldsymbol{Q}$ in the sense of Pollak (1969) or Browning and Meghir (1991). This structure produces particular restrictions on household behavior as the same function $\rho$ appears in all of the demands. Compared to equation (6), the distribution factors now have an income effect through the sharing rule. In addition, Bourguignon, Browning, and Chiappori (2009) derive particular constraints, in the form of partial differential equations, which private demands need to satisfy in the particular case where prices are constant. They also show that a minimum of three separate demands are in general necessary for household behavior to be constrained.

The question of the allocation of public goods has only been treated more recently in the literature. ${ }^{17}$ In particular, Donni (2009) shows that the (inverse) demands for public goods have to have a fairly comparable structure to those for private goods. The demands for public goods are thus implicitly defined as follows:

$$
\boldsymbol{P}=\boldsymbol{P}_{A}(\boldsymbol{p}, \boldsymbol{Q}, \rho(y, \boldsymbol{p}, \boldsymbol{Q}, \boldsymbol{s}))+\boldsymbol{P}_{B}\left(\boldsymbol{p}, \boldsymbol{Q}, y^{*}-\rho(y, \boldsymbol{p}, \boldsymbol{Q}, \boldsymbol{s})\right),
$$

where the functions $\boldsymbol{P}_{A}(\cdot)$ and $\boldsymbol{P}_{B}(\cdot)$ denote the individual prices (that is, the Lindahl prices) at which the household members value the public goods,

\footnotetext{
${ }^{17} \mathrm{~A}$ preliminary analysis of the constraints due to the presence of public goods was carried out by Chiuri and Simmons (1997).
} 
and $\rho$ as previously.

To conclude, the demands for exclusive goods can be written in an analogous manner whether the good be public or private. Imagine that good 1, for example, is exclusively consumed by household member $i$. If the econometrician considers that this is an exclusive public good, its inverse demand can be written as below:

$$
P^{1}=P_{i}^{1}\left(\boldsymbol{p}, \boldsymbol{Q}, \rho_{i}(y, \boldsymbol{p}, \boldsymbol{Q}, \boldsymbol{s})\right),
$$

where $p^{1}=0$ and $\rho_{i}$ do not include expenditure on good 1 (as good 1 is a public good). However, the exclusive good is most often considered to be private, for simplicity's sake. Then, the demand for this good is written as:

$$
q^{1}=q_{i}^{1}\left(\boldsymbol{p}, \boldsymbol{Q}, \rho_{i}(y, \boldsymbol{p}, \boldsymbol{Q}, \boldsymbol{s})\right),
$$

where $Q^{1}=0$ and $\rho_{i}$ now include the expenditure on good 1 (as good 1 is a private good). The most important point here is that the demands for public and private goods by one household member do not depend on the price of the exclusive goods consumed by his or her partner - except via the sharing rule. We can thus show that the presence of these goods produces greater restrictions, which are formally derived in a series of theoretical contributions including, amongst others, Chiappori $(1988,1992)$, Bourguignon, Browning and Chiappori (2009), Donni (2007), and Chiappori, Fortin and Lacroix (2002).

\subsection{Conditional Demands}

In the context of collective models, one type of conditional demand is of particular interest. Consider, for example, the demand for good $k$, denoted 
by $\xi^{k}$, and suppose that this demand can be locally inverted with respect to a distribution factor (say $s_{1}$ ). We then have:

$$
s_{1}=s_{1}^{k}\left(y, \xi^{k}, \boldsymbol{\pi}, \boldsymbol{s}_{-1}\right),
$$

where $s_{-1}$ is the vector of distribution factors with the first element removed. The substitution of this function into the demands for the goods $k^{\prime} \neq k$ yields the following conditional demand:

$$
\xi^{k \prime}=\xi_{c}^{k^{\prime}}\left(y, \xi^{k}, \boldsymbol{\pi}, \boldsymbol{s}_{-1}\right)
$$

These demands, known as "s-conditional demands", turn out to be very useful as a way of expressing the different constraints due to Pareto efficiency. For example, Bourguignon, Browning and Chiappori (2009) show that the proportionality condition can be transposed very simply as follows:

$$
\frac{\partial \xi_{c}^{k^{\prime}}}{\partial \boldsymbol{s}_{-1}^{\prime}}=0
$$

In what follows, we will refer to "implicit proportionality" to make clear that this condition applies to the conditional demands. Donni (2006) equally derives an implicit transposition of the SR1 condition with a set of additional hypotheses over preferences and goods, while Donni and Moreau (2007) adapt s-conditional demands to the question of labor supply.

There are other ways in which demands can be usefully expressed in the collective framework. Donni (2009), as does Mazzocco (2004) in a somewhat different context, considers a form of demands where the good under consideration is a function of the demands for two goods. These represent the distribution factors $s$ and income $y$. These demands, known as "cmdemands", are valuable for the analysis of cooperative models, in particular 
if we suppose that agents are egotistical and that the conditioning goods are exclusive.

\section{Cooperative Models - Identification}

This section asks the following question: given that household demands are observed, what can we say about the structural components of the decision process that led to them, that is, the utility functions and the function $\mu$ ? This question has been answered in a number of different ways in the recent literature. Indeed, rather than a general theory of identification, the literature has provided a scattered set of results based on particular hypotheses. In the following we will attempt to present the most important of these results.

As a preliminary, we should note that in a general model where the preferences are given by equation (2), it is simply not possible to identify the decision process. ${ }^{18}$ Additional hypotheses over goods or preferences are necessary for identification to be feasible. In the following, we thus imagine that preferences are as given in equation (3) and that public and private goods are disjoint. We consider first of all the case where all goods are private, and then afterwards all of the other cases.

\subsection{The Case of Private Goods Only}

As noted above, under the preceding hypotheses, Pareto efficiency has one attractive consequence: that of being able to split the decision process up into two stages. Without public goods, the demands for private goods can

\footnotetext{
${ }^{18} \mathrm{~A}$ formal proof of this statement is provided in Chiappori and Ekeland (2009).
} 
then be written as follows:

$$
\boldsymbol{q}=\boldsymbol{q}_{A}(\boldsymbol{p}, \rho(y, \boldsymbol{p}, \boldsymbol{s}))+\boldsymbol{q}_{B}(\boldsymbol{p}, y-\rho(y, \boldsymbol{p}, \boldsymbol{s})) .
$$

When all goods are private, the decentralization of the decision-making process can be seen as a simple corollary of the Second Fundamental Theorem of Welfare Economics. Moreover, the relationship between the functions $\mu(y, \boldsymbol{p}, \boldsymbol{s})$ and $\rho(y, \boldsymbol{p}, \boldsymbol{s})$ is bijective, so that these functions are equivalent representations of the distribution of power within the household. Even so, the representation in terms of the sharing rule is often preferable, as it is invariant to a positive monotonic transformation of the utility functions. Nonetheless, the sharing rule no longer constitutes an adequate measure of the distribution of power as soon as some of the goods are public - even though it still exists in this case, as we saw in the preceding section.

When all goods are private, Bourguignon, Browning and Chiappori (2009) show that some derivatives of the sharing rule can be identified from observed behavior. More precisely: ${ }^{19}$

Proposition 1 If a set of three demands for three goods is observed, and if $K \geqslant 4$ and $J \geqslant 1$, the sharing rule $\rho$ is identified up to a function $k(\boldsymbol{p})$; this function is homogeneous of degree 1 in $\boldsymbol{p}$.

In other words, if the sharing rule $\rho^{*}(y, \boldsymbol{p}, \boldsymbol{s})$ is compatible with a set of three private goods demands, then any other rule $\rho(y, \boldsymbol{p}, \boldsymbol{s})$ which is compatible

\footnotetext{
${ }^{19}$ Our objective in the following propositions is to set out a number of the main identification results. However, all of these results require regularity conditions, sometimes very complex, that it would be too tedious to list here. Information on these is available in the cited articles.
} 
with the same set of demands will necessarily have the following form:

$$
\rho(y, \boldsymbol{p}, \boldsymbol{s})=\rho^{*}(y, \boldsymbol{p}, \boldsymbol{s})+k(\boldsymbol{p})
$$

where $k(\boldsymbol{p})$ is a linear homogeneous function. In particular, if prices do not change, which will in principle be the case in cross-section data, this indetermination then boils down to a constant. Note that the identification of the derivatives of the sharing rule does not require the observation of demands at the individual level. The mechanism of resource-sharing within the household can be analyzed via the estimation of a system of demands.

In certain situations, it is possible to reduce this indetermination regarding the function $k(\cdot)$. To this end, the econometrician needs information on one or more exclusive goods. Suppose that good 1 (resp. 2) is exclusively consumed by member $A$ (resp. $B$ ). From equation (11), we know that the demands for exclusive goods can be written as follows:

$$
\begin{aligned}
q^{1} & =q_{A}^{1}\left(p_{1}, \boldsymbol{p}_{-2}, \rho(y, \boldsymbol{p}, \boldsymbol{s})\right) \\
q^{2} & =q_{B}^{2}\left(p_{2}, \boldsymbol{p}_{-2}, y-\rho(y, \boldsymbol{p}, \boldsymbol{s})\right),
\end{aligned}
$$

where $\boldsymbol{p}_{-2}$ denotes the vector of prices $\boldsymbol{p}$ with its first two elements removed. Some simple manipulations of these equations shows that the indifference curves of the sharing rule can be recovered. If we consider equation (13), for example, we can identify the slopes of these curves:

$$
\frac{\partial \rho}{\partial s_{l}} / \frac{\partial \rho}{\partial y}=\frac{\partial q^{1}}{\partial s_{l}} / \frac{\partial q^{1}}{\partial y} \quad \text { and } \quad \frac{\partial \rho}{\partial p_{2}} / \frac{\partial \rho}{\partial y}=\frac{\partial q^{1}}{\partial p_{2}} / \frac{\partial q^{1}}{\partial y}
$$

where the terms on the right-hand side are observable; we can carry out an analogous procedure in the case of (14). This information on the sharing 
rule is invaluable, and as a result the identification of the sharing rule from exclusive goods is in general more robust.

In more detail, Chiappori and Ekeland (2009) and Chiappori, Fortin and Lacroix (2002) prove the following result:

Proposition 2 If the demands for goods 1 and 2 are observed, and good 1 (resp. 2) is exclusively consumed by member $A$ (resp. B), and if $J \geqslant 1$, the sharing rule $\rho$ is identified up to a function $\boldsymbol{p}_{-2}$; this function is homogeneous of degree 1 in $\boldsymbol{p}_{-2}$.

In other words, the derivative of the sharing rule with respect to the price of exclusive goods can be identified. Furthermore, we only need to observe the demands for two goods, as opposed to three in the preceding case. Chiappori $(1988,1992)$ shows that distribution factors are not totally indispensable for identification. These do however produce more robust identification and are necessary if we consider the price of exclusive goods to be constant.

These theoretical results have inspired a substantial empirical literature. For example, Browning, Bourguignon, Chiappori and Lechene (1994) consider a theoretical framework where prices are constant, and estimate the sharing rule on Canadian data under the hypothesis that male and female clothing are exclusive goods. They show that the sharing of household resources is a function of the labour earnings of husband and wife. Other authors, whose work will be described in more detail below, use these theoretical results in the context of labor supply, where leisure is considered to be an exclusive good. Finally, Bourguignon, Browning and Chiappori (2009) and Donni (2006) consider the theoretical case where the econometrician 
only observes one exclusive good, and an aggregated good, and reach similar conclusions to those in propositions 1 and 2 .

\subsection{The Case of Public Goods Only}

The literature on the possibility of identifying the structural elements of household behavior when consumption is public is only recent. When the econometrician observes demands for two exclusive goods, Chiappori and Ekeland (2009), and Donni (2009) with another proof technique, prove the following powerful result.

Proposition 3 If a complete system of demands is observed and good 1 (resp. 2) is exclusively consumed by member A (resp. B), the utility functions are identified up to a monotone transformation. For any choice of cardinalization, the $\mu$ function is exactly identified.

As such, all the structural components of the model are identifiable, and this identification is not conditional on an unknown constant. This result does not depend on distribution factors. On the contrary, we do need to observe the complete system of demands to recuperate the utility functions, but this is also the case in the unitary model.

\subsection{The General Case of private and public goods}

If some goods are private and others public, the identification question becomes much more complicated and there is no general solution to the problem at time of writing. Some important components of the structural model can 
however be identified. To show this, we define the "collective" indirect utility functions $v_{i}^{*}(y, \boldsymbol{p}, \boldsymbol{P}, \boldsymbol{s})$ by substituting demand functions for private and public goods into the direct utility functions. This yields:

$$
v_{i}^{*}(y, \boldsymbol{p}, \boldsymbol{P}, \boldsymbol{s})=u_{i}(\boldsymbol{q}(y, \boldsymbol{p}, \boldsymbol{P}, \boldsymbol{s}), \boldsymbol{Q}(y, \boldsymbol{p}, \boldsymbol{P}, \boldsymbol{s})) .
$$

This expression describes the level of welfare that member $i$ attains in the household when he or she faces the price-income bundle $(\boldsymbol{p}, \boldsymbol{P}, y)$ and a set of distribution factors $s$. This representation of utility differs from the "unitary" indirect utility function in that it implicitly includes an outcome of the collective decision process. In the case where certain private goods are consumed exclusively by one or the other of the household members, Chiappori and Ekeland (2009) proves the following result:

Proposition 4 If a complete system of demands for goods is observed, and private good 1 (resp. 2) is exclusively consumed by member A (resp. B), the indirect collective utility functions are identified up to a monotonic transformation. For any choice of cardinalization, the $\mu$ function is exactly identified.

This result is important because it gives us the opportunity to carry out wellbeing analysis, not at the household but at the individual level. Blundell, Chiappori and Meghir (2005) propose a similar analysis with respect to labor supply (see below). Donni (2006) show that the indirect collective utility function can be identified, using the observation of only one exclusive good, in the case where all goods are private. 


\subsection{Single People's Preferences and the Behavior of Married Couples}

In the work described above, one of the principal difficulties comes from the fact that individual preferences are unknown, and have to be estimated from behavior (at the same time as the Pareto weights). One possible solution is to appeal to other sources of information to estimate preferences. In practice, this most often consists in the use of data on single people to estimate individual preferences, and then to use the results of these estimations in the analysis of couple behavior, which allows us in general to identify exactly the decision process. A general presentation of this procedure is contained in Laisney (eds, 2006).

The identification of household decision-making from the behavior of single people does of course raise a number of particular problems. In the first instance, there is obviously the danger of selection bias, in the sense that the marriage decision will likely depend on preferences. To avoid this stumbling block, it is useful to have panel data available in which the same individuals are followed over time and are observed at different periods both as single or divorced, and married. Recent work by Couprie (2007) appeals to this idea to analyze labor supply in the context of domestic production, which we will return to below.

Even if the correction bias is corrected, other problems remain. We know, for example, that the consumption structure of couples is qualitatively different from that of singles ("one and one don't make two", to cite the title of an article by Vermeulen and Watteyne, 2006). Browning, Chiappori and Lewbel (2006) propose a solution which avoids supposing that preferences 
change (in good methodological practice, changes in preferences are only invoked as a last resort). It is supposed that individual preferences remain the same whatever the marital status, but introduce the Beckerian idea of a domestic production technology which is particular to couples - either because the consumption of certain goods is associated with economies of scale, or more generally because the complementarity or substitutability between goods might be different for couples. They show that for a general linear technology it is possible to identify all of the structural elements of the model (both the decision-making process and the production technology) when estimating the demands of the single and couples. These methods have the additional advantage of supplying a new and probably more operational definition of the concept of an equivalence scale. ${ }^{20}$

\section{Cooperative Models - Applications and Extensions}

\subsection{Labor Supply Models}

Labor supply models are amongst the oldest to have appealed to the cooperative approach, having started at the beginning of the $1980 \mathrm{~s}^{21}$ In these models, the leisure of household members is typically considered as an exclusive good, while the other goods, which are of only secondary importance,

\footnotetext{
${ }^{20}$ See also Lewbel and Pendakur (2008) on this.

${ }^{21}$ The first contributions to the cooperative theory of labor supply include, amongst others, Apps (1981, 1982), Apps and Jones (1986), and Apps and Rees (1988). This research was in general based on less general hypotheses than those used in later work.
} 
are aggregated into a Hicksian good with a price that is supposed equal to one. $^{22}$

Labor supply models are distinctive in the first instance by the hypotheses that are made with respect to the nature of the goods and the form of preferences. If consumption is private, and if agents are egotistical, the utility functions can be written as follows:

$$
U_{i}\left(T-h_{i}, q_{i}\right),
$$

where $h_{i}$ denotes the labor supply of member $i, q_{i}$ their private consumption, and $T$ total available time. The price of leisure of member $i$, in other words their hourly wage, is denoted by $w_{i}$. As we saw above, the decision process can be decentralized. In the first stage, household members receive an equal allocation of $\rho_{i}$, with $\rho_{A}+\rho_{B}=y$, where $y$ designates the net spending of the household (i.e. total spending, including spending on leisure, from which the value of the time endowment, $T w_{A}+T w_{B}$, is subtracted). In the second stage, each individual maximizes their utility without taking their partner's behavior into account. In this case, labor supplies are of the following form:

$$
h_{i}=h_{i}\left(w_{i}, \rho_{i}\left(y, w_{A}, w_{B}, \boldsymbol{s}\right)\right) .
$$

It is to be noted here that the labor supply of individual $i$ depends only on her own wage and her endowment, in particular, the wage and endowment of her partner play a part only via the sharing rule.

The identification results presented above can be readily applied here. It is clear, from proposition 2, that the sharing rule can be identified up to $a$

\footnotetext{
${ }^{22}$ This last seems like a natural hypothesis as, in labor-supply models, the consumption price is generally considered to be constant.
} 
constant (as the price of the aggregate good is constant). Moreover, proposition 4 implies that the collective indirect utility function can be retrieved as well. This gives us the opportunity to carry out well-being analysis, not at the household but at the individual level. Last, note that the identification of the sharing rule does not require any distribution factors here; the presence of these latter will nonetheless produce more robust estimation results.

The theory of cooperative models of labor supply is extended by Donni (2003) to include the treatment of corner solutions and non-linear budget constraints. In addition, Blundell, Chiappori, Magnac and Meghir (2007) consider the situation where female labor supply is continuous whereas male labor supply is discrete, and show that the sharing rule can equally be recovered in this case. Last, a great number of empirical applications have appealed to the theoretical framework developed above. Fortin and Lacroix (1997) use Canadian data to test the constraints of the model: the results show that these are rejected for a sample of couples without children. They also estimate the parameters of the sharing rule, but these are not estimated particularly precisely. Chiappori, Fortin and Lacroix (2002) appeal to data from the Panel Study of Income Dynamics and obtain much more precise estimates of the structural parameters. One of the reasons for this greater precision is their introduction of appropriate distribution factors into the analysis, in this case variables relating to the marriage market and the legislation of marriage. Moreau and Donni (2002) also introduce distribution factors, applied to French data, and take into account the non-linearity of taxation. Other empirical analyses in the same vein include Bloemen (2009), Clark, Couprie and Sofer (2004) and Vermeulen (2005) on Dutch, British 
and Belgian data respectively.

The hypothesis on the private nature of consumption can easily be relaxed. For example, Donni (2007) consider egotistical individuals with the following preferences:

$$
U_{i}\left(T-h_{i}, Q\right),
$$

where $Q$ is a Hicksian good which represents public consumption. Under this hypothesis, and taking into account the property of homogeneity, labor supplies can be written as below:

$$
h_{i}=h_{i}\left(\frac{w_{i}}{\pi_{i}\left(y, w_{A}, w_{B}, \boldsymbol{s}\right)}, \frac{\rho_{i}\left(y, w_{A}, w_{B}, \boldsymbol{s}\right)}{\pi_{i}\left(y, w_{A}, w_{B}, \boldsymbol{s}\right)}\right),
$$

where

$$
\pi_{i}\left(y, w_{A}, w_{B}, s\right)=\frac{h_{i} w_{i}+\rho_{i}\left(y, w_{A}, w_{B}, s\right)}{y+h_{A} w_{A}+h_{B} w_{B}}
$$

denotes member $i$ 's Lindahl price for the public good. Proposition 3, adapted to the case of labor supply, implies that the utility functions are identified up to a positive transformation.

A wide variety of other models of labor supply have recently been proposed. ${ }^{23}$ Blundell, Chiappori, and Meghir (2005) have developed a model where consumption consists of a public good and a private good. The utility functions then are of the following form:

$$
U_{i}\left(l_{i}, q_{i}, Q\right)
$$

Blundell, Chiappori and Meghir then advance that the collective indirect utility functions can be identified up to a positive transformation. This result

\footnotetext{
${ }^{23}$ We do not discuss below those which are inspired by the theory of revealed preferences; see Chiappori (1988) and Seaton $(1997,2000)$ on this subject.
} 
is a variation of proposition 4 . However, to facilitate identification, they use a distribution factor.

In addition, Fong and Zhang (2001) question the idea that leisure is an exclusive good and adopt a novel approach to the problem. They imagine that leisure can be decomposed into private leisure (that agents use independently from each other) and public leisure (that agents enjoy together). Preferences have a separable structure and are written as follows:

$$
U_{i}\left(u_{i}\left(l_{i}, q_{i}\right), L\right)
$$

where $L$ denotes public leisure and $l_{i}$ private leisure. The important point in their analysis is that, in general, the econometrician only observes the total leisure of each member, that is $\ell_{i}=l_{i}+L$. It can then be shown that, with the help of exclusive goods and distribution factors, that the two components of leisure can be identified. This result is of particular interest as it shows how the identification question can be treated in the case where public and private goods are not disjoint.

\subsection{Domestic Production}

One natural generalization of the above models is to include domestic production. Apps and Rees (1997), Chiappori (1997), and then Donni (2008), all suppose that preferences also cover the consumption of a good which is produced within the household. The utility functions then have the following form:

$$
U_{i}\left(l_{i}, q_{i}, z_{i}\right)
$$


where $z_{i}$ is produced with the technology:

$$
z_{A}+z_{B}=F\left(t_{A}, t_{B}\right)
$$

where $F$ is a constant - or decreasing - returns to scale production function, and $t_{i}$ is the time devoted by household member $i$ to domestic production. If domestic labor supplies, as well as market labor supplies, are observed, and the domestic good is tradeable, then identification of preferences and the sharing rule does not pose any particular problem. However, if the domestic good is not tradeable, so that its price is endogenous to the household decisions, identification raises problems which have not yet been entirely solved. This model, and variants of it, have been empirically analyzed in a number of contributions. For example, Apps and Rees (1996), Rapoport, Sofer and Solaz (2004) and van Klaveren, van Praag and Maassen van den Brink (2007) estimate the canonical model with Australian, French and Dutch data, respectively. Couprie (2003) considers a model where the domestic good is public, and presents empirical results from British data. Udry (1996) takes a radically different approach to test efficiency in a sample of rural households where Agricultural production is carried out using different plots of land. Productive efficiency here requires that domestic labor supplies are determined such that average productivity is the same for all of the plots of land that the household cultivates, independently of the identity of the individual who owns the plot. This condition is tested and rejected using data from Burkina Faso. 


\subsection{Choice under Uncertainty}

Once we accept that households need to be analyzed as a group of individuals, rather than as a single decision-making center, any situation involving uncertainty should be considered in the framework of risk-sharing within the household. This type of analysis raises a number of interesting problems. First, we can consider the conditions under which a household will behave, as seen from the outside, like a single decision-maker. The work of Wilson (1968), extended by Mazzocco (2005), shows that an exact aggregation of this type is only possible under restrictive conditions: technically, risk aversion has to be of the "harmonic risk-aversion" (HARA) type, with in addition the same coefficient for all of the household members (ISHARA). ${ }^{24}$ If this is not the case, then the analysis of the sharing of risk within the household is complex. Mazzocco shows that an increase in the risk aversion of one individual can reduce the risk aversion exhibited by the group.

We may, in addition, try to measure the extent of risk-sharing within the household. This was the subject of a great deal of research in the past (see Hayashi, Altonji and Kotlikoff, 1996, for example), the principal implication of efficiency in this context is well-known: when exogenous income is subject

${ }^{24}$ The utility function $u_{i}$ of individual $i$ has to be such that :

$$
-\frac{u_{i}^{\prime \prime}\left(q_{i}\right)}{u_{i}^{\prime}\left(q_{i}\right)}=\frac{1}{a_{i}+b q_{i}}
$$

where the coefficient $b$ is identical for all of the individuals. Utility functions are therefore of the form

$$
u_{i}\left(q_{i}\right)=\frac{1}{b-1}\left(a_{i}+b q_{i}\right)^{1-\frac{1}{b}} .
$$


to random fluctuations, the consumption of any one individual should not be affected by their own individual risk, but only by the aggregate risk. This "mutuality principle" has been applied on a number of occasions to the problem of risk-sharing in rural villages in developing countries, starting with the contribution of Townsend (1994). To apply these results at the household level, however, requires that we face the traditional problem of the non-observation of individual consumption levels. Chiappori (1999) tackles this problem by extending the existing results to the situation where agents are able to adjust their labor supply in response to random shocks. He then shows that labor supplies should then depend only on total exogenous household income, and not on variations in its components due to random shocks. In other words, the income aggregation condition holds in a collective model with uncertainty. In addition, the sharing rule which results from the sharing of risk between household members has to satisfy a restriction with takes the form of a partial differential equation. This model has not to date been estimated empirically. However, Dercon and Krishnan (2000) is also on the subject of risk-sharing, and presents results from Ethiopian data. The underlying idea in this paper is to use a measure of health, which is observed at the individual level, to pick up the effect of shocks on incomes.

\subsection{Intertemporal Choice}

These difficulties are also found in collective models of intertemporal consumption, ${ }^{25}$ but we have in addition a more fundamental problem: a poten-

\footnotetext{
${ }^{25}$ Browning $(1995,2000)$ was among the first contributions to analyze intertemporal choice in the context of a collective model. He also emphasizes the different problems that
} 
tial challenge to the paradigm of Pareto efficiency, at least in its strongest sense. This latter supposes that household members are able to commit to long-term engagements; technically, the Pareto weights are invariant over time, and independent of any shocks which hit the household. This is a strong hypothesis, particularly in a context where divorce is possible (and agents cannot commit not to divorce). Recent work has however suggested first a way of empirically testing the validity of this hypothesis, and second a more general formulation of the problem which allows this hypothesis to be relaxed.

Technically, if risk-sharing is efficient, and if utility functions are intertemporally additive, the problem facing the household in period 0 is the following:

$$
\max _{\substack{q_{A}^{t}, q_{B}^{t} \\ \forall t, \omega}} \mu(\boldsymbol{\theta}) \cdot E_{0}\left(\sum_{t=0}^{T} \frac{u_{A}\left(q_{A}^{t}(\omega)\right)}{(1+\delta)^{t}}\right)+(1-\mu(\boldsymbol{\theta})) \cdot E_{0}\left(\sum_{t=0}^{T} \frac{u_{B}\left(q_{B}^{t}(\omega)\right)}{(1+\delta)^{t}}\right),
$$

under a stochastic intertemporal budget constraint, where $\omega$ is the state of nature, $\delta$ is the discount rate, and $q_{i}^{t}(\omega)$ is the consumption of household member $i$ in period $t$ in state $\omega$. The strongest form of efficiency (full-commitment efficiency) implies that no renegotiation of a pre-existing agreement take place. The function $\mu$ is then fixed at the beginning of the planning horizon, taking into account the full set of characteristics of the distribution of prices and incomes (represented by the parameter vector $\boldsymbol{\theta}$ ), and remains constant over the entire life cycle. A weaker form of efficiency (limited-commitment efficiency) consists of supposing that participation constraints are satisfied at each time period and for each state of nature. Formally, this yields a series are encountered in such estimations. 
of additional constraints such that:

$$
E_{\tau}\left(\sum_{t=0}^{T-\tau} \frac{u_{i}\left(q_{i}^{t+\tau}(\omega)\right)}{(1+\delta)^{t}}\right) \geqslant \bar{U}_{i}^{t+\tau}(\boldsymbol{\theta}, \omega),
$$

for all $\tau>0$ and all $\omega$, where $\bar{U}_{i}^{t+\tau}(\boldsymbol{\theta}, \omega)$ are utility thresholds. ${ }^{26}$

Recent work has looked at the theoretical properties of this model. Mazzocco (2005) considers the allocation of consumption over two periods, and notably produces a paradoxical result: everything else equal, risk-sharing within the household may produce a higher level of saving, even when the individual utility function have all of the standard properties (prudence etc.). Again, this paradox only disappears if preferences are of the "ISHARA" type. Mazzocco (2007) shows that, in households with more than one individual, the Euler equation, which describes the intertemporal allocation of consumption, will in general depend on the distribution of bargaining power, that is of the Pareto weights. ${ }^{27}$ Here again, household behavior can be described by a traditional Euler equation (corresponding to a unitary utility function $\left.U\left(q_{A}^{t}+q_{B}^{t}\right)\right)$ only if preferences are ISHARA. When this is not the case, any parameter which affects the Pareto weights will also have an impact on the

\footnotetext{
${ }^{26}$ Basu (2006) considers a different type of inefficiency in the intertemporal context, due to current actions affecting future bargaining power; this endogenization of the Pareto weights may provide an incentive for certain households not to exploit all of the potential efficiency gains. Lundberg and Pollak (2003) continue with this idea, with an example based on the location choice of the couple, and insist on the role of particular decisions which may change the stationary character of the household's environment. These inefficiencies disappear once we allow household members to commit contractually. Further contributions in the same vein are Konrad and Lommerud (2000) and Lundberg (2002).

${ }^{27}$ Lich-Tyler $(2001,2003)$ also considers Euler equations in the framework of an intertemporal model, and reaches similar conclusions.
} 
Euler equations, even if all of the other properties of the model (perfect financial markets, rational expectations, etc.) are satisfied. As a result, the classic test of intertemporal behavior, that the marginal expected utility of future consumption depend only on current marginal utility (and not on the current values of other variables, such as incomes) will be in general inappropriate in the case of household data, at least in the case, which is likely true, that preferences are not ISHARA and current incomes are correlated with the Pareto weights. Mazzocco (2003) carries out empirical tests of these ideas on American data, and finds that the classic conditions hold for singles, but not for couples.

If we imagine that bargaining power may change over time (in the absence of full-commitment efficiency), and that preferences are ISHARA, the traditional Euler equation is replaced by a super-martingale condition:

$$
\frac{\partial U\left(q^{t}\right)}{\partial q^{t}}>E_{t}\left(\frac{1+r_{t+1}}{1+\delta} \cdot \frac{\partial U\left(q^{t+1}\right)}{\partial q^{t+1}}\right)
$$

where $q^{t}=q_{A}^{t}+q_{B}^{t}$, and $r_{t}$ is the interest rate in period $t$. The intuition behind this result is that agents decide to save more when they are faced with a new kind of risk (due to fluctuations in bargaining power). ${ }^{28}$ Mazzocco (2007) uses these properties to test model of efficiency with commitment, which is rejected in favor of a weaker version of efficiency.

One drawback is that the model does not produce any specific predictions regarding the constraints on behavior if preferences are not ISHARA. This comes from the fact that individual consumptions are not observed. However,

\footnotetext{
${ }^{28}$ Aura (2004) obtains a similar result with a less general model.
} 
consider the case of the following utility function:

$$
E_{0}\left(\sum_{t=0}^{T} \frac{u_{i}\left(l_{i}^{t}, q_{i}^{t}\right)}{(1+\delta)^{t}}\right),
$$

where $l_{i}^{t}$ is the leisure of household member $i$ in the period $t$. This latter can be interpreted as an exclusive good. Appealing to a type of cm-demands, Mazzocco (2004) then shows that, in this case, the individual Euler equations can be recovered, and that the model can be tested.

Further empirical work has considered less general questions. Lundberg, Startz and Stillman (2001) develop a model of the intertemporal allocation of consumption that is particularly aimed at explaining why consumption drops sharply at the time of retirement. Seitz (2008) builds and estimates a dynamic model of marriage-market equilibrium in order to establish the link between the characteristics of this market and the observed behavioral differences between Blacks and Whites in terms of marriage, divorce and employment.

\subsection{More than Two People in the Household}

It is fairly simple to generalize the preceding models to greater numbers of decision-makers. Consider then that the household consists of $N \geqslant 2$ individuals, and that the members of this household have utility functions as given by (2). Chiappori and Ekeland (2006) then show that the PseudoSlutsky matrix $\mathbf{S}$ has to satisfy the following $\mathrm{SNR}(\mathrm{N}-1)$ condition:

$$
\mathbf{S}=\mathbf{\Sigma}+\mathbf{R}(N-1)
$$

where $\boldsymbol{\Sigma}$ is a negative semi-definite matrix, and $\mathbf{R}(N-1)$ is a matrix of rank $N-1$. This condition is restrictive if the number of goods is sufficiently high. 
Both Dauphin and Fortin (2001) and Chiappori and Ekeland (2006) analyze the implications of distribution factors on household demands. They show that

$$
\operatorname{rang}\left(\frac{\partial \boldsymbol{\xi}}{\partial \boldsymbol{s}^{\prime}}\right) \leqslant N .
$$

This condition is obviously only restrictive if the number of distribution factors is greater than $N$. The condition is tested by Dauphin and Fortin (2001) and Dauphin (2003) on a sample from Burkina Faso including bigamous households, and by Kapan (2009) on Turkish data.

To conclude, Bourguignon (1999) proposes a model of consumption, without price effects, in a three-person household. His main objective is to analyze the conditions under which the mechanism of resource allocation between household members can be recovered. Individual preferences are imagined to be as in (3), and all goods are considered to be private. ${ }^{29}$ The decisionmaking process, as in traditional models, can be decomposed into two stages. Household members first agree on a split of the household's resources between themselves, and then maximize their utilities. In this case, and under a certain number of conditions (notably that there are both exclusive goods and distribution factors), the derivatives of the sharing rule can be recovered.

\footnotetext{
${ }^{29}$ In fact, Bourguignon (1999) analyzes a household with two parents and one child. He imagines that the parents hold all of the bargaining power, and are altruistic. The utility functions are as in (4), and include as arguments, the utilities of each of the parents and of the child. However, the analysis requires that each household member have a different Pareto weight. Our presentation in terms of three symmetrical individuals is thus more appropriate.
} 


\subsection{Bargaining and Threat Points}

The cooperative models that we have discussed above are in fact generalizations of more specific models based on the axiomatic theory of bargaining. These latter are typically built up from the idea that household decisions can be represented by Nash (or Kalai-Smorodinsky) bargaining. In its most general form, agents' behavior is then described by the programme below:

$$
\max _{\boldsymbol{q}_{A}, \boldsymbol{q}_{B}, \boldsymbol{Q}}\left(U_{A}\left(\boldsymbol{q}_{A}, \boldsymbol{q}_{B}, \boldsymbol{Q}\right)-V_{A}\right) \times\left(U_{B}\left(\boldsymbol{q}_{A}, \boldsymbol{q}_{B}, \boldsymbol{Q}\right)-V_{B}\right)
$$

subject to the budget constraint (1), where $V_{i}$ is the threat point of member $i$, that is, the utility that this member would enjoy if there is no bargaining agreement. This threat point depends in general on a variety of variables, including the distribution factors.

The distinction between the different bargaining models boils down to the choice of threat point. ${ }^{30}$ Manser and Brown (1980) and McElroy and Horney (1981) imagine that this latter is represented by the individual's utility in the case of divorce. ${ }^{31}$ For example, the threat points could be written as follows:

$$
V_{i}\left(y_{i}, w_{i}, c_{i}, m_{i}\right)
$$

where $y_{i}$ represents the income of member $i$ after divorce, $w_{i}$ the wage rate, $c_{i}$ the share of divorce costs that $i$ would have to pay, and $m_{i}$ is an indicator related to the marriage market which reflects remarriage opportunities. However, imagining that the principal threat in a household is that of divorce may seem rather excessive. Lundberg and Pollak (1993) therefore

\footnotetext{
${ }^{30}$ Ligon (2002) proposes a different type of model, where the Nash solution is generalized to an intertemporal framework (and the hypothesis of efficiency is relaxed).

${ }^{31}$ Ott (1990) presents a certain number of extensions of this model.
} 
developed a model where the threat point is determined by the solution to a non-cooperative game. ${ }^{32}$ In this model, certain types of spending belong to the masculine sphere, and others to the feminine sphere. If the couple decides not to cooperate, each household member will carry out the spending in their own sphere, subject to their own budget constraint. Bergstrom (1999) attempts to unite this literature by building a model, inspired by the foundations of non-cooperative bargaining theory (as in Rubinstein and Binmore), where divorce is only the ultimate threat, in the sense that the level of utility cannot fall below that which would pertain in the case of divorce. ${ }^{33}$

The question of the empirical content of bargaining models was the subject of hot debate a number of years ago, and the following conclusions seem to have been drawn (see Chiappori (1988b, 1991), McElroy and Horney (1990) and McElroy (1990)). In the first instance, the demands resulting from the programme in (16) naturally have to satisfy the conditions derived in Section 2 as these bargaining models with symmetric information lead to efficient allocations. The problem is then the following: does the hypothesis that individual behavior is described by Nash bargaining lead to any additional constraints? This point is complicated by the fact that neither individual preferences nor the threat points are observed by the econome-

\footnotetext{
${ }^{32}$ Chen and Woolley (2000) also propose a bargaining model where the threat points are given by the level of utility that would be obtained in a non-cooperative game. However, their model, perhaps surprisingly, does not yield Pareto-efficient outcomes. It is therefore difficult to classify this model in the cooperative group.

${ }^{33}$ Kanbur and Haddad $(1992,1994)$ and Haddad and Kanbur (1992) appeal to bargaining models to consider the relationship between economic growth and within-household inequality.
} 
trician, and it is not even possible to estimate them on a sample of single or divorced individuals as the concepts of utility that appear in (16) have a cardinal dimension. However, one possible response to this question has recently been proposed. Chiappori and Donni (2008) show that if we have no a priori information on the threat points, then bargaining models produce no new predictions that can be tested empirically. The underlying idea is that any point along the Pareto frontier can be achieved by the judicious choice of the threat points. Even so, bargaining models will yield additional empirical content as long as preferences and threat points satisfy a particular separability property. This is in particular the case when agents are egotistical, when there are no externalities, and when the threat points are of the type given by (17). Furthermore, under certain additional hypotheses, it is even possible to identify the cardinal utility functions.

\section{Non-cooperative Models}

Non-cooperative models are based on game theory, and more specifically on Cournot-Nash equilibria. The principle here is that household members act to maximize their own utility subject to their own budget constraint, while taking the decisions of their partner into account. First suppose that household income $y$ is divided up between the household members according to some rule, and that as a result member $A$ receives $\rho_{A}$ and member $B \rho_{B}$.

When preferences are as (3), and public and private goods are disjoint, the 
demands resulting from the Cournot-Nash equilibrium are given by ${ }^{34}$

$$
\max _{\boldsymbol{q}_{i}, \boldsymbol{Q}_{i}} U_{i}\left(\boldsymbol{q}_{A}, \boldsymbol{Q}_{A}+\boldsymbol{Q}_{B}\right) \text { subject to } \boldsymbol{p}^{\prime} \boldsymbol{q}_{i}+\boldsymbol{P}^{\prime} \boldsymbol{Q}_{i}=\rho_{i}(y, \boldsymbol{p}, \boldsymbol{P}, \boldsymbol{s}),
$$

where $\boldsymbol{Q}_{i}$ denotes the contribution of member $i$ to the provision of public goods. This presentation of the problem is similar to the decentralization of the allocation of private goods in cooperative models. There is nonetheless an essential difference here, in that the decentralization here simultaneously covers both private and public goods. Consequently, the allocation of goods that results will be inefficient. ${ }^{35}$ It should be noted, however, that cooperative and non-cooperative models will produce the same outcomes if all goods are private and there are no externalities.

The solution of the programme (18) produces reaction functions and solving them with respect to $\left(\boldsymbol{q}_{i}, \boldsymbol{Q}_{i}\right)$ gives the Cournot-Nash equilibrium. Browning, Chiappori and Lechene (2009) and Ulph (2006) analyze the existence conditions of this equilibrium and the properties of the resulting demand functions. The former authors show that, in general, household members will contribute to the provision of no more than one public good. One remarkable result, in the very case where the provision of one public good is made by both household members, is that the demands for goods do not depend on the initial division of exogenous income. In other words, if we analyze the couple's demands, at a given total level of income, as a function

\footnotetext{
${ }^{34}$ This specification is reminiscent of that in Carter and Katz (1997) where, before the game starts, agents divide household income up according to what the authors call a "conjugal contract".

${ }^{35} \mathrm{~A}$ decentralized decision-making process will lead to Pareto-efficient allocations if personal prices, that is the Lindahl prices, are defined in a first stage. This point was briefly mentioned in Section 4.
} 
of the initial split of this income, we will obtain a "plateau" on which these demands are independent of this split; in particular, the income pooling condition is satisfied. However, for a very unequal distribution of income, one of the members will stop contributing to the public good, and we will return to the case where demands are indeed a function of the initial distribution of income. This is a generalization of a well-known result in Public Economics due to Warr (1983), Kemp (1984) and Bergstrom, Blume and Varian (1988). This conclusion also applies, mutatis mutandis, to cooperative models in which the non-cooperative outcome acts as the threat point.

While one of the conditions that characterizes the unitary model, that is the aggregation of income, is satisfied by the goods demands that result from the non-cooperative model, the symmetry condition in general is not. Considering the special case where $\rho_{i}(y, \boldsymbol{p}, \boldsymbol{P}, \boldsymbol{s})=y_{i}$, where $y_{i}$ is the income of member $i$, Ulph (2006) has shown that the Pseudo-Slutsky matrix will be symmetric in the special case where preferences depend only on public goods or the endowment of household members is very unequal. Lechene and Preston (2009) show that, in general, if the number of public goods is equal to $M$ and the number of private goods is sufficiently large, the PseudoSlutsky matrix $\mathbf{S}$ satisfies the following condition:

$$
\mathbf{S}=\boldsymbol{\Sigma}+\mathbf{R}(M+1)
$$

where $\mathbf{R}(M+1)$ is a matrix of rank $M+1$. As such, the price effects have to satisfy a certain restriction, but this latter is weaker than that which pertains in cooperative models.

The non-cooperative framework has also been applied to labor supply. Donni (2006) considers a fairly general form of preferences, which are as 
follows:

$$
U_{i}\left(l_{A}, l_{B}, q_{A}, q_{B}\right)
$$

where $l_{i}$ denotes the leisure of member $i$ and $q_{i}$ their consumption; these variables create an externality on the well-being of the individual's partner. In this general model, as there are no public goods, strictly speaking, the distribution factors may affect household behavior. However, if stronger hypotheses on preferences are adopted, then the empirical content of the model is considerably richer. For example, Ulph (1981) and Kooreman and Kapteyn (1990) estimate the labor supplies which result from preferences of the following type:

$$
U_{i}\left(l_{A}, l_{B}, Q_{A}+Q_{B}\right)
$$

In this case, the presence of public consumption implies that the aggregation condition of income is satisfied and the initial division of income will have no effect on outcomes. Some elements of individual preferences can equally be recovered. More precisely, the general solution for the preferences of member $i$, as a function of the labor supplies, is given by:

$$
F\left(U_{i}\left(l_{A}, l_{B}, Q\right), l_{i}\right)
$$

where $U_{i}\left(l_{A}, l_{B}, q\right)$ is a particular solution and $F(\cdot)$ is a positive function of $U_{i}$. Leuthold (1968), in what is very likely the first article on "formal" nonunitary models, considers another special case and supposes that preferences are given by:

$$
U_{i}\left(l_{i}, Q_{A}+Q_{B}\right) .
$$


The drawback of this specification is that it is not possible to take into account any complementarity or substitutability between the leisure of different household members. Other labor supply models where consumption is partly public and partly private are proposed by Bourguignon (1984).

To conclude, it should be noted that many household decisions are analyzed in a non-cooperative framework. Bjorn and Vuong $(1984,1997)$ and Kooreman (1994) adapt non-cooperative models of labor supply to discrete choices ${ }^{36}$ while Konrad and Lommerud (1995) and Carter and Katz (1997) concentrate on domestic production. Konrad and Lommerud (2000) analyze over-investment in human capital in both cooperative and non-cooperative models. This list is far from being exhaustive.

\section{Conclusion}

In this article, we have seen that non-unitary models of household behavior can be split up into two broad categories. The first includes non-cooperative (or strategic) models, which are based on Cournot-Nash equilibria, and the second cooperative (or collective) models which only posit the Pareto efficiency of allocations. Recent research appears to have shown, nonetheless, that the interactions between these two categories of model are increasingly important. As we have seen, cooperative models which are based on bargaining theory sometimes use the utility levels that would prevail under a non-cooperative game between household members as threat points. Further, the analysis of intertemporal choice models has often led to the abandon of

\footnotetext{
${ }^{36}$ They also consider models based on Stackelberg equilibria.
} 
the hypothesis of Pareto-efficiency. On the one hand, Pollak and Lundberg (1994) have become the advocates of a more general model, based on repeated games and which often exhibits a number of different Cournot-Nash equilibria. Some of these equilibria are efficient, but others are not, and the choice between the different equilibria is determined by cultural factors. On the other hand, Kaushik Basu, Ethan Legon, Stephen Lich-Tyler, Maurizio Mazzoco, in addition to a number of other authors, whose work was discussed in Sections 4.3 et 4.4, emphasize that Pareto efficiency is more difficult to justify in an intertemporal context. If household members are not able to pre-commit contractually, changes in the opportunities that become open to them over time will yield changes in negotiating power, and thus inefficiency. The analysis of household behavior in this framework constitutes vast research program.

Recent work has also moved towards the use of collective models in economic policy. For example, Lise and Seitz (2008) consider the distribution of income, both between and within households. Laisney (eds, 2006) discusses an ambitious research project the objective of which is to analyze the effects of fiscal reform on labor supply. On this score, empirical models which are based only on Pareto efficiency raise a certain number of problems: as they do not explicitly specify the threat points of household members, nor the type of bargain which underlies outcomes, they are not strictly speaking structural models. In other words, the form of the sharing rule cannot be explained by these models. A substantial degree of caution is therefore required if we wish to use the results of this analysis to simulate the effects of economic policy. An example may help to make this point clearer. As we saw 
above, Marjorie McElroy and Mary-Jane Horney choose the level of utility that household members would obtain when divorced as the threat point. One implication of this hypothesis is that any change in the identity of the beneficiary of family support will have no effect on household behavior (as family support automatically goes to the individual who keeps the children in the case of divorce). Alternatively, Shelly Lundberg and Robert A. Pollak suppose that the threat point is determined by the levels of utility that each household member would obtain if they were to carry out the tasks that are traditionally assigned to their gender. In this case, a change in the beneficiary of family support will likely affect the distribution of resources within the household. In other words, empirical analysis based on Pareto efficiency can yield diverse predictions with respect to behavior, because there is no theory to determine the sharing rule. The solution to this problem is likely found in the use of richer data in which we are able to observe exogenous changes in both the amount of child benefits and other family support and the way in which these are allocated within the family, or in the development of more restrictive theoretical models which also explain the distribution of resources within the household. This constitutes one of the main challenges facing researchers in the area of the Economics of the Household. 
Appendix : Empirical Applications of Non-unitary Models

\begin{tabular}{|c|c|c|c|}
\hline AUTHORS & MODELS & DATA & $\begin{array}{c}\text { TESTS AND } \\
\text { IDENTIFICATION }\end{array}$ \\
\hline \multicolumn{4}{|c|}{ Non-cooperative models } \\
\hline Ashworth and Ulph (1981) & $\begin{array}{l}\text { Labor supply equations; public } \\
\text { consumption and externalities }\end{array}$ & $\begin{array}{l}\text { Survey of Social Science Research } \\
\text { Counsil, } 1971 \text { (United Kingdom) }\end{array}$ & - \\
\hline Bjorn and Vuong (1985) & Participation equations & PSID, 1982 (United States) & - \\
\hline Bjorn and Vuong (1997) & Participation equations & PSID, 1982 (United States) & $\longrightarrow$ \\
\hline Donni (2006) & $\begin{array}{l}\text { Labor supply equations; private and } \\
\text { public consumption, and externalities }\end{array}$ & PSID, 1990 (United States) & Tests of negativity and particular tests \\
\hline Leuthold (1968) & $\begin{array}{l}\text { Labor supply equations; public } \\
\text { consumption; linear expenditure } \\
\text { system }\end{array}$ & $\begin{array}{l}\text { Survey of Survey Research Center of } \\
\text { the University of Michigan, } 1959 \\
\text { (United States) }\end{array}$ & $\longrightarrow$ \\
\hline Kooreman (1994) & Participation equations & $\begin{array}{l}\text { Dutch Labor Mobility Survey, } 1985 \\
\text { (Netherlands) }\end{array}$ & $\begin{array}{l}\text { Tests of various models (Nash and } \\
\text { Stackelberg) }\end{array}$ \\
\hline Kooreman and Kapteyn (1990) & $\begin{array}{l}\text { Labor supply equations; public } \\
\text { consumption and externalities; linear } \\
\text { expenditure system }\end{array}$ & $\begin{array}{l}\text { Dutch Labor Mobility Survey, } 1982 \\
\text { (Netherlands) }\end{array}$ & $\longrightarrow$ \\
\hline
\end{tabular}

Cooperative models of consumption and labor supply in a static environment

Apps and Rees (1996)

Aronsson, Daunfeldt and Wikstrom (2001)

Basu and Ray (2002)

Bloemen (2009)

Blundell, Chiappori, Magnac andMeghir (2007)

Bourguignon, Chiappori, Browning and Lechene (1993)

Browning and Chiappori (1998)

Browning, Bourguignon, Chiappori and Lechene (1994)

Carrasco and Zamora (2007)

Chiappori, Fortin and Lacroix (2002) Market labor supply equations;

Clark, Couprie and Sofer (2004)

Couprie (2007)

Dauphin (2003) goods women's participation decisions
Labor supply equations and leisure demand equations; domestic cost function

Market labor supply equations and one domestic labor supply equation

Children's labor supply equations

Labor supply equations; participation decisions

Women's labor supply equation and Family Expenditure Survey, 1978-

men's participatin equation

ABS Income Distribution Survey, 1987 (Australia)

Survey of Household Market and (Sweden) 1990-2001.

1993 (United Kingdom) 1985-86; ABS Time Use Pilot Survey, Nonmarket Activities, 1984 et 1993

Nepal Living Standards Survey, 1995 Tests of the link between labor supply and bargaining power

Socio-Economic Panel (Netherlands), Estimation of the sharing rule

Particular tests; estimation of the sharing rule

Demand equations for private goods Budget des familles, 1984-85 (France) Proportionality tests

Demand equations for impure goods Family Expenditure Survey, 19741992 (Canada)

SR1, linearity and proportionality tests

Demand equations for exclusive Family Expenditure Survey, 19741992 (Canada)

Particular tests; estimation of the sharing rule

Demand equations for impure goods; Encuesta de Presupuestos Familiares, regime switchings as a function of the 1990-91 (Spain) distribution factors: sex ratio and dummies for marriage/divorce laws

PSID, 1988 (United States)

Labor supply equations

Market and domestic labor supply equations
British Household Panel Survey, 1997 (United Kingdom)

British Household Panel Survey, 1992-2000 (United Kingdom)
Proportionality tests and particular tests; estimation of the sharing rule

Particular tests, estimation of the sharing rule

Estimation of the sharing rule
Demand equations for impure goods; Survey of CRDI, 2002 (Burkina Faso) Proportionality tests household with more that two

decision-makers 
Donni (2007)

Donni (2009)

Fortin and Lacroix (1997)

Browning, Chiappori and Lewbel (2006)

Luo (2002)

Moreau and Donni (2002)

Rapallini (2004)

Seaton (2001)

Thomas and Chen (1995)

Vermeulen (2005)

Vermeulen (2006)

Zamora (2009)
Women's labor supply equation and demand equations for private goods

Demand equations for private and public goods; cm-demands;

conditioning goods: male and female clothing

Labor supply equations

Demand equations for goods and production technology

Demand equations for impure goods Family Expenditure Survey, !9781986 (Canada)

Labor supply equations; distribution Panel INSEE, 1994 (France) factor: sex ratio

Demand equations for exclusive goods

Consumption Survey ISTAT, 1999 (Italy)

Family Expenditure Survey, 1984

(United-Kingdom)

Demand equations for private goods Personal Survey of Income Distribution,1980 (Taiwan)

Market labor supply equations Belgian Socio-Economic Panel, 1992 and 1997 (Belgium)

Belgian Socio-Economic Panel, 1992 Particular tests; estimation of the and 1997 (Belgium)

supply equations

Encuesta de Presupuestos Familiares, Particular tests; estimation of the 1990-91 (Spain) goods; regime switchings as a

function of the women's participation

decisions sharing rule

Particular tests and proportionality tests; estimation of the sharing rule

Estimation of the sharing rule, and of the production technology; various

R1, linearity and proportionality ests

Particular tests; estimation of the sharing rule

Particular tests, estimation of the sharing rule

Non-parametric tests

Proportionality tests

Particular tests; and estimation of the haring rule haring rule

sharing rule

\section{Other cooperative models}

Dercon and Krishnan (2000)

Lundberg, Startz, and Stillman (2001)

Mazzocco (2003)

Mazzocco (2004)

Udry (1997)
Equations of nutritional statute

Euler equations

Demand equation for intertemporal consumption; cm-demands; conditioning good: leisure

Equations of productivity
Ethiopian Rural Household Survey, Tests of efficient risk sharing 1994-1995 (Ethiopia)

PSID, 1979-86 and 1989-92 (United Tests of consumption smoothing States (after retirement)

PSID, 1975-1987; Consumer Tests of Euler equations on singles Expenditure Survey, 1980-95 (United and couples States)

Consumer Expenditure Survey, 1982- Tests of Euler equations; particular 1998 (Unitd States)

Survey of International Crops Tests of productive efficiency

Research Institute for the Semi-Arid Tropics, 1981-1983 (Burkina Faso) 


\section{References}

[1] Alderman H, P.A. Chiappori, L. Haddad, J. Hoddinott and R. Kanbur, 1995, "Unitary versus Collective Models of the Household: Is It Time to Shift the Burden of the Proof", World Bank Research Observer, vol. 10, pp. $1-19$.

[2] Altonji J.G., F. Hayashi and L. Kotlikoff, 1992, "Is the Extended Family Altruistically Linked? Direct Tests Using Micro-data", American Economic Review, vol. 82, pp. 1177-1198.

[3] Apps P.F., 1981, A Theory of Inequality and Taxation, Cambridge: Cambridge University Press.

[4] Apps P.F., 1982, "Institutional Inequality and Tax Incidence", Journal of Public Economics, vol. 18, pp. 217-242.

[5] Apps P.F. and G.S. Jones, 1986, "Selective Taxation of Couples", Zeitscrift für Nationalökonomie, vol.5 (supplement), pp. 63-74.

[6] Apps P.F. and R. Rees, 1988, "Taxation and the Household", Journal of Public Economics, vol. 35, pp. 355-369.

[7] Apps P.F. and R. Rees, 1996, "Labour Supply, Household Production and Intra-family Welfare Distribution", Journal of Public Economics, vol. 60, pp. 199-219.

[8] Apps P.F. and R. Rees, 1997, "Collective Labour Supply and Household Production", Journal of Political Economy, vol. 105, pp. 178-190. 
[9] Apps P.F. and R. Rees, 2009, Public Economics and the Household, Cambridge University Press, Cambridge.

[10] Aronsson T., S.O. Daunfeldt and M. Wikström, 2001, "Estimating Intrahousehold Allocation in a Collective Model with Household Production", Journal of Population Economics, vol. 14, pp. 569-584.

[11] Aura, S., 2004, "Uncommitted Couples: Some Eficiency and Policy Implications of Marital Bargaining", Working Paper no. 04-08, Department of Economics, University of Missouri.

[12] Basu K., 2006, "Gender and Say: A Model of Household Behavior with Endogenously-determined Balance of Power", Economic Journal, vol. 116, pp. 558-580.

[13] Basu K. and R. Ray, 2002, "The Collective Model of the Household and An Unexpected Implication for Child Labor: Hypothesis and an Empirical Test", Policy Research Working Papers Series 2813, The World Bank.

[14] Becker G.S., 1974, "A Theory of Social Interactions", Journal of Political Economy, vol. 82, pp. 1063-1093.

[15] Becker G.S., 1991, A Treatise on the Family, Enl. Edition, Cambridge University Press.

[16] Becker G.S. and K.M. Murphy, 2000, Social Economics, MA: Harvard University Press. 
[17] Behrman J., 1988, "Intrahousehold Allocation of Nutrients in Rural India: Are Boys Favoured? Do Parents Exhibit Inequality Aversion?", Oxford Economic Papers, vol. 40, pp. 32-54.

[18] Bergstrom T., 1989, "A Fresh Look at the Rotten-Kid Theorem and Other Household Mysteries", Journal of Political Economy, vol. 97, pp. $1138-1159$.

[19] Bergstrom T., 1996, "Economics in a Family Way", Journal of Economic Literature, vol. 34, pp. 1903-1934.

[20] Bergstrom T., L. Blume and H. Varian, 1986, "On the Private Provision of Public Goods", Journal of Public Economics, vol. 29, pp. 25-49.

[21] Bjorn P.A. and Q.H. Vuong, 1985, "Econometric Modeling of a Stackelberg Game with an Application to Labor Force Participation", Social Science Working Paper 577, California Institute of Technology.

[22] Bjorn P.A. and Q.H. Vuong, 1997, "Modèle d'équations simultanées pour variables endogènes fictives: une formulation par la théorie de jeux avec application à la participation au marché du travail", Actualité économique: revue d'analyse économique, vol. 73, pp. 161-205.

[23] Bloemen, H., 2009, "An Empirical Model of Collective Household Labour Supply with Nonparticipation", Economic Journal (forthcoming).

[24] Blundell, R., P.A. Chiappori, T. Magnac, and C. Meghir, 2007, "Collective Labor Supply: Heterogeneity and Non-participation", Review of Economic Studies, vol. 74, pp. 417-445. 
[25] Blundell, R., P.A. Chiappori P.A., and C. Meghir, 2005, "Collective Labour Supply with Children", Journal of Political Economy, vol. 105, pp. 1277-1306.

[26] Bourguignon F., 1984, "Rationalité individuelle ou rationalité stratégique: le cas de l'offre familiale de travail", Revue économique, vol. 1, pp. 147-162.

[27] Bourguignon F., 1999, "The Cost of Children: May the Collective Approach to Household Behaviour Help?", Journal of Population Economics, vol. 12, pp. 503-522.

[28] Bourguignon F., M. Browning and P.A. Chiappori, 2009, "Efficient Intra-household Allocations and Distribution Factors: Implications and Identification", Review of Economic Studies, vol. 76, pp. 503-528.

[29] Bourguignon F., M. Browning, P.A. Chiappori and V. Lechene, 1993, "Intra Household Allocation of Consumption: A Model and Some Evidence from French Data", Annales d'économie et de statistique, vol. 29 , pp. $137-156$.

[30] Bourguignon F. and P.A. Chiappori, 1992, "Collective Models of Household Behavior: An Introduction", European Economic Review, vol. 36, pp. 355-364.

[31] Brett C., 1998, "Tax Reform and Family Decision-making", Journal of Public Economics, vol. 70, pp. 425-440.

[32] Browning M., 1996, "Saving and the Intra-household Allocation of Income", Ricerche Economiche, vol. 48, pp. 277-292. 
[33] Browning M., 2000, "The Saving Behaviour of a Two-person Household", Scandinavian Journal of Economics, vol. 102, pp. 235-251.

[34] Browning M., F. Bourguignon, P.A. Chiappori and V. Lechene, 1984, "Income and Outcomes: A Structural Model of Intrahousehold Allocation", Journal of Political Economy, vol. 102, pp. 235-251.

[35] Browning M. and P.A. Chiappori, 1998, "Efficient Intrahousehold Allocations: A General Characterization and Empirical Tests", Econometrica, vol. 66, pp. 1241-1278.

[36] Browning M., P.A. Chiappori, and V. Lechène, 2006, "Collective and unitary models: a clarification", Review of Economics of the Household, Volume 4, Number 1, 5-24.

[37] Browning M., P.A. Chiappori, and V. Lechène, 2008, "Distributional Effects in Household Models: Separate Spheres and Income Pooling", Economic Journal (forthcoming).

[38] Browning M., P.A. Chiappori and A. Lewbel, 2006, "Estimating Consumption Economies of Scale, Adult Equivalence Scales, and Household Bargaining Power", Manuscript, Oxford University Press.

[39] Browning M. and C. Meghir, 1991, "The Effect of Male and Female Labor Supply on Commodity Demands", Econometrica, vol. 59, pp. 925-951.

[40] Carrasco R., and B. Zamora, 2007, "The Causal Effect of Female Labour Participation on Household Consumption", Manuscript, University Carlos III. 
[41] Carter M.R. and E. Katz, 1997, "Separate Sphere and the Conjugal Contract: Understanding the Impact of Gender-biased Development". In: Haddad L., Hoddinott J. and Alderman H. (eds), Intrahousehold Resource Allocation in Developing Countries, Baltimore and London: The John Hopkins University Press.

[42] Chen Z. and F. Woolley, 2000, "A Cournot-Nash Model of Family Decision Making", Economic Journal, Vol. 111, pp. 722-48.

[43] Cherchye, L., B. De Rock and F. Vermeulen, 2007, "The Collective Model of Household Consumption: A Nonparametric Characterization", Econometrica, vol. 75, 553-574.

[44] Cherchye, L. and F. Vermeulen, 2008, "Nonparametric Analysis of Household Labor Supply: Goodness-of-fit and Power of the Unitary and the Collective Model", Review of Economics and Statistics, vol. 90, pp. 267-274.

[45] Chiappori P.A., 1988a, "Rational Household Labor Supply", Econometrica, vol. 56, pp. 63-89.

[46] Chiappori P.A., 1988b, "Nash-bargained Household Decisions: A Comment", International Economic Review, vol. 29, pp. 791-796.

[47] Chiappori P.A., 1990, "Nash-bargained Household Decisions: A Rejoinder", International Economic Review, vol. 32, pp. 761-762.

[48] Chiappori P.A., 1992. "Collective Labor Supply and Welfare", Journal of Political Economy, vol. 100, pp. 437-467. 
[49] Chiappori P.A., 1997, "Collective Models of Household Behavior: The Sharing Rule Approach". In: Haddad L., Hoddinott J. and Alderman H. (eds), Intrahousehold Resource Allocation in Developing Countries, Baltimore and London: The John Hopkins University Press.

[50] Chiappori P.A., 1997, "Introducing Household Production in Collective Models of Labor Supply", Journal of Political Economy, vol. 105, pp. $191-$

[51] Chiappori P.A and O. Donni, 2008, "Learning from a Piece of Pie: The Empirical Content of Nash Bargaining", Manuscript, Columbia University.

[52] Chiappori P.A. and I. Ekeland, 2006, "The Micro-economics of Group Behavior: General Characterization", Journal of Economic Theory, vol. 130, pp. 1-26.

[53] Chiappori P.A. and I. Ekeland, 2009, "The Micro-economics of Efficient Group Behavior: Identification", Econometrica, vol. 77, pp. 763-794.

[54] Chiappori P.A, B. Fortin and G. Lacroix, 2002, "Household Labor Supply, the Sharing Rule and the Marriage Market", Journal of Political Economy, vol. 110, pp. 37-72.

[55] Chiuri M.C. and P. Simmons, 1997, "Universal Decentralisation: A Demand System For Collective and Unitary Models With Household Public Goods", Economic Journal, vol. 107, pp.372-389 
[56] Chiuri M.C., 2000, "Individual Decisions and Household Demand for Consumption and Leisure", Research in Economics, vol. 54, pp. 277324.

[57] Clark A., H. Couprie and C. Sofer, 2004, "La modélisation collective de l'offre de travail: mise en perspective et application", Revue économique, vol. 56, pp. 277-284.

[58] Couprie H., 2007, "Time Allocation within the Family: Welfare Implication of Life in Couple", Economic Journal, vol. 117, pp. 287-305.

[59] Dauphin A., 2003, "Rationalité collective des ménages comportant plusieurs membres: résultats théoriques et applications au Burkina Faso", Thèse de doctorat, Université Laval.

[60] Dauphin A. and B. Fortin, 2001, "A Test of Collective Rationality for Multi-person Households", Economic Letters, vol. 71, pp. 211-216.

[61] Dercon S. and P. Krishnan, 2000, In Sickness and in Health: Risk Sharing within Households in Rural Ethiopia", Journal of Political Economy, vol. 108, pp. 688-727.

[62] Donni O., 2003, "Collective Household Labor Supply: Nonparticipation and Income Taxation", Journal of Public Economics, vol. 87, pp. $1179-1198$.

[63] Donni O., 2006, "Collective Consumption and Welfare", Canadian Journal of Economics, vol. 39, pp. 124-144. 
[64] Donni O., 2006, "Les modèles non coopératifs d'offre de travail: théorie et évidence", Actualité économique: revue d'analyse économique, vol. 82 , pp. $181-206$.

[65] Donni O., 2007, "Collective Female Labour Supply: Theory and Application", Economic Journal, vol. 117, pp. 94-119.

[66] Donni O., 2007, "Choix collectif du temps travaillé, consommation publique, et équilibre de Lindahl", Revue économique, vol. 58, pp. 535543.

[67] Donni O., 2008, "Labor Supply, Domestic Production, and Welfare Comparisons", Journal of Public Economics, vol. 92, pp. 1720-1737.

[68] Donni O., 2009, "A Simple Approach to Investigate Intra-household Allocation of Private and Public Goods", Review of Economics and Statistics, vol. 91, pp. 617-628.

[69] Donni O. and N. Moreau, 2007, "Collective Labor Supply: A Singleequation Model and Some Evidence from French Data", Journal of Human Resources, vol. 42, pp. 214-246.

[70] Duflo E., 2000, "Child Health and Household Resources: Evidence from the South African Old-Age Pension Program", American Economic Review, Papers 6 Proceedings, vol. 90, pp. 393-398.

[71] Fong Y.and J. Zhang, 2001, "The Identification of Unobservable Independent and Spousal Leisure", Journal of Political Economy, vol. 109, pp. 191-202. 
[72] Fortin B. and G. Lacroix, 1997, "A Test of the Collective and Unitary Model of Labour Supply", Economic Journal, vol. 107, pp. 933-955.

[73] Folbre N., 1986, "Cleaning House", Journal of Development Economics, vol. 2, pp.5-40.

[74] Folbre N., 1997, "Gender Coalitions: Extrafamily Influences on Intrafamily Inequality". In: Haddad L., Hoddinott J. and Alderman H. (eds), Intrahousehold Resource Allocation in Developing Countries, Baltimore and London: The John Hopkins University Press.

[75] Gersbach H. and H. Haller, 2001, "Collective Decisions and Competitive Markets", Review of Economic Studies, vol. 68, pp. 347-368.

[76] Gray, J.S., 1998, "Divorce-Law Changes, Household Bargaining, and Married Women's Labor Supply", American Economic Review, vol. 88, pp. 628-642.

[77] Grossbard-Schechtman S. and S. Neuman, 2003, Marriage and Work for Pay. In: Grossbard-Schechtman S. (eds), Marriage and the Economy: Theory and Evidence from Advanced Societies, Cambridge, UnitedKingdom: Cambridge University Press,

[78] Haddad L. and J. Hoddinott, 1994, "Women's Income and Boy-girl Anthropometric Status in the Côte d'Ivoire", World Development, vol. 22, pp. 543-553.

[79] Haddad L. and R. Kanbur, 1992, "Intrahousehold Inequality and the Theory of Targeting", European Economic Review, vol. 36, pp. 372377. 
[80] Haddad L. and R. Kanbur, 1992, "Is There an Intrahousehold Kuznets Curve? Some Evidence from the Philippines", Public Finance, vol. 47 (supplement), pp. 77-93.

[81] Hayashi F., J.G. Altonji and L.F. Kotlikoff, 1996, "Risk-sharing between and within Families", Econometrica, vol. 64, pp. 261-294.

[82] Kanbur R. and L. Haddad, 1994, "Are Better Off Households More Onequal or Less Unequal?", Oxford Economic Papers, vol. 46, pp. 445458.

[83] T. Kapan (2009), Essays on Household Behavior, PhD dissertation, Columbia University.

[84] Kemp M., 1984, "A note on the theory of international transfers", Economics Letters, vol. 14, pp. 259-262.

[85] Klassen S., 1998, "Marriage, Bargaining, and Intrahousehold Resource Allocation: Excess Female Mortality among Adults during Early German Development, 1740-1860", Journal of Economic History, vol. 58, 432-467.

[86] van Klaveren, C., B. van Praag and H. Maassen van den Brink (2007), "Empirical Estimation Results of a Collective Household Time Allocation Model", Review of Economics of the Household (forthcoming).

[87] Konrad K.A. and K.E. Lommerud, 1995, "Family Policy with Noncooperative Families", Scandinavian Journal of Economics, vol. 97, pp. 581-601. 
[88] Konrad K.A. and K.E. Lommerud, 2000, "The Bargaining Family Revisited", Canadian Journal of Economics, vol. 33, pp. 471-486.

[89] Kooreman P., 1994, "Estimation of Econometric Models of some Discrete Games", Journal of Applied Econometrics, vol. 9, pp. 255-268.

[90] Kooreman P., 2000, "The Labelling Effect of a Child Benefit System", American Economic Review, vol. 90, pp.571-583.

[91] Kooreman P. and A. Kapteyn, 1990, "On the Empirical Implementation of some Game Theoretic Models of Household Labor Supply", Journal of Human Resources, vol. 25, pp. 584-598.

[92] Laisney F. (eds), 2006, "Welfare Analysis of Fiscal and Social Security Reforms in Europe: Does the Representation of Family Decision Process Matter?", Review of Economics of the Household, vol. 4, pp. 99-180.

[93] Leuthold J., 1968, "An Empirical Study of Formula Transfers and the Work Decision of the Poor", Journal of Human Resources, vol. 1, pp. 312-323.

[94] Lechene V. and O. Attanasio, 2002, "Tests of Income Pooling in Household Decisions", Review of Economic Dynamics, vol. 5, pp. 720-748

[95] Lechene V. and I. Preston, 2000, "Noncooperative Household Demand", Working Paper WP08/14, The Institute for Fiscal Studies.

[96] Lewbel A. and K. Pendakur, 2008, "Estimation of Collective Household Models With Engel Curves," Journal of Econometrics, special issue on 
Estimating Demand Systems and Consumer Preferences, vol. 147, pp. $350-358$.

[97] Lich-Tyler S., 2001, "The Dynamics of Bargained Household Decisions", Manuscript, University of Texas at Austin.

[98] Lich-Tyler S., 2003, "The Consumption Dynamics and Savings Behavior of Pluralistic Households", Manuscript, University of Michigan at Ann Arbor.

[99] Ligon E., 2002, "Dynamic Bargaining in Households (with an Application to Bangladesh)", Working Paper CUDARE 972, University of California at Berkley.

[100] Lise J. and S. Seitz, 2008, "Consumption Inequality and Intrahousehold Allocations", Manuscript, Queen's University.

[101] Lundberg S. and R.A. Pollak, 1993, "Separate Spheres Bargaining and the Marriage Market", Journal of Political Economy, vol. 101, pp. 9881010.

[102] Lundberg S. and R.A. Pollak, 1994, "Non-cooperative Bargaining Models of Marriage", American Economic Review (Papers 8 Proceedings), vol. 84, pp. 132-137.

[103] Lundberg S. and R.A. Pollak, 1996, "Bargaining and Distribution in Marriage", Journal of Economic Perspectives, vol. 10, pp. 139-158.

[104] Lundberg S. (2002), "Limits to Specialization: Family Policy and Economic Efficiency", Manuscript, University of Washington. 
[105] Lundberg S. and R.A. Polak, 2003, "Efficiency in Marriage", Review of Economics of the Household, vol. 1, pp. 153-167.

[106] Lundberg S., R.A. Pollak and T. Wales, 1997, "Do Husbands and Wives Pool their Resources? Evidence from the UK Child Benefit", Journal of Human Resources, vol. 32, pp. 463-480.

[107] Lundberg S., R. Startz and S. Stillman, 2003, "The RetirementConsumption Puzzle: A Marital Bargaining Approach", Journal of Public Economics, vol. 87, pp. 1199-1218.

[108] Luo G.Y., 2002, "Collective-Decision Making and Heterogeneity in Tastes", Journal of Business and Economics Statistics, vol. 20, pp. $213-226$.

[109] Manser M. and M. Brown, 1980, "Marriage and Household Decisionmaking: A Bargaining Analysis", International Economic Review, vol. 21, pp. 31-44.

[110] Mazzocco M., 2003, "Intertemporal Behavior and Household Structure", Manuscript, University of Wisconsin-Madison.

[111] Mazzocco M., 2004, "Individual Euler Equations rather than Household Euler Equations", Manuscript, University of Wisconsin-Madison.

[112] Mazzocco M., 2005, "Savings, Risk Sharing and Preferences For Risk", American Economic Review, vol. 94, pp. 1169-1182. 
[113] Mazzocco M., 2007, "Household Intertemporal Behavior: A Collective Characterization and a Test of Commitment", Review of Economic Studies, vol. 79, pp. 857-895.

[114] McElroy M.B. and M.J. Horney, 1981, "Nash-bargained Household Decisions: Toward a Generalization of the Theory of Demand", International Economic Review, vol. 22, pp. 333-349.

[115] McElroy M.B., 1990, "The Empirical Content of Nash-bargained Household Behavior", Journal of Human Resources, vol. 25, pp. 559583.

[116] McElroy M.B., 1997, "The Policy Implications of Family Bargaining and Marriage Markets". In: Haddad L., Hoddinott J. and Alderman H. (eds), Intrahousehold Resource Allocation in Developing Countries, Baltimore and London: The John Hopkins University Press.

[117] Moehling C., 2005, " 'She has suddenly become powerful': Youth Employment and Household Decision-Making in the Early Twentieth Century", Journal of Economic History, vol. 65, pp 414-438.

[118] Moreau N. and O. Donni O., 2002, "Un modèle collectif d'offre de travail avec taxation", Annales d'économie et de statistique, vol 65, pp. $55-81$.

[119] Orefficce S., 2007, "Did the Legalization of Abortion Increase Women's Household Bargaining Power: Evidence from Labor Supply", Review of Economics of the Household, vol. 5, pp.. 
[120] Ott N., 1992, Intrafamily bargaining and household decisions. Berlin: Springer Verlag.

[121] Phipps S. and P. Burton, 1992, "What's Mine is Yours? The Influence of Male and Female Incomes on Patterns of Household Expenditure", Economica, vol. 65, pp. 599-613.

[122] Pollak R.A., 1969, "Conditional Demand Function and Consumption Theory", Quarterly Journal of Economics, vol. 83, pp. 70-78.

[123] Pollak R.A., 1977, "Price Dependent Preferences", American Economic Review, vol. 67, pp. 64-75.

[124] Pollak R.A., 1985, "A Transaction Cost Approach to Families and Households", Journal of Economic Literature, vol. 23, pp. 581-608.

[125] Rapallini C., 2004, "Scelte di consumo e modello colletivo: test della razionalità colletiva e stima della regola di ripartizione con i dati italiani" ("Consumption choices and collective models: testing collective rationality and the sharing rule with italian data"), Rivista di Politica Economia, vol. 9-10, pp.249-271.

[126] Rapoport B., C. Sofer, A. Solaz, 2009, "Household Production in a Collective Model: Some New Results", Journal of Population Economics (forthcoming).

[127] Rubalcava L. and D. Thomas, 2005, "Family Bargaining and Welfare", Manuscript, University of California at Los Angeles. 
[128] Robin J.M. and R. Smith, 2000, "Test of Rank", Econometric Theory, vol. 16, pp. 151-175.

[129] Samuelson P., 1956, "Social Indifference Curves", Quarterly Journal of Economics, vol. 70, pp. 1-22.

[130] Schultz T.P., 1990, "Testing the Neoclassical Model of Family Labor Supply and Fertility", Journal of Human Resources, vol. 25, pp. 599631.

[131] Seaton J.S., 1997, "Neoclassical and Collective Rationality in Household Labour Supply", Applied Economics Letters, vol. 4, vol. 529-533.

[132] Seaton J.S., 2001, "Bargaining versus Non-cooperation; Transaction Costs within Marriage", Applied Economics Letters, vol. 8, pp. 37-41.

[133] Seitz S., 2008, "Accounting for Racial Differences in Marriage and Employment", Manuscript, Queen's University.

[134] Strauss J, G. Mwabu and K. Beegle K., 2000, "Intraousehold Allocations: A Review of Theories and Empirical Evidence", Journal of African Economies, vol 9 (AERC supplement), pp. 83-143.

[135] Thomas D., 1990, "Intra-household Resource Allocation: An Inferential Approach", Journal of Human Resources, vol. 25, pp. 635-664.

[136] Thomas D., 1992, "The Distribution of Income and Expenditures within the Household", Annales d'économie et de statistique, vol. 29, pp. 109-135. 
[137] Thomas D., 1994, "Like Father, like Son: like Mother, like Daughter: Parental Resources and Child Height", Journal of Human Resources, vol. 25, pp. 950-988.

[138] Thomas D. and C.L. Chen, 1994, "Income Shares and Shares of Income: Empirical Tests of Models of Household Resources Allocations", Working Paper 94-08, RAND, University of California at Los Angeles.

[139] Thomas D., D. Contreras, E. Frankenberg, 2004, "Child Health and the Distribution of Household Resources at Marriage", Manuscript, University of California at Los Angeles.

[140] Townsend R. (1994), "Risk and Insurance in Village India", Econometrica, 62, 539-591.

[141] Udry C., 1996, "Gender, Agricultural Production, and the Theory of the Household", Journal of Political Economy, vol. 104, pp. 1010-1046.

[142] Ulph D., 2006, "Un modèle non-coopératif de Nash appliqué à l'étude du comportement de consommation du ménage", Actualité économique: revue d'analyse économique, vol. 82, pp. 53-86.

[143] Vermeulen F., 2002, "Collective Household Models: Principles and Main Results", Journal of Economic Surveys, vol. 16, pp. 533-564.

[144] Vermeulen F., 2005, "And the Winner is... An Empirical Evaluation of Two Competing Approaches to Household Labour Supply", Empirical Economics, vol. 30, pp. 711-734. 
[145] Vermeulen F., 2006, "A Collective Model for Female Labour Supply with Nonparticipation and Taxation", Journal of Population Economics, vol. 19, pp. 99-118.

[146] Vermeulen F. and A. Watteyne, 2006, "Quand un et un ne font plus deux. Calcul d'échelles d'équivalences intrafamiliales au moyen d'un modèle collectif", Actualité économique: revue d'analyse économique, vol. 82, 155-180.

[147] Warr P., 1983, "The Private Provision of a Public Good Is Independent of the Distribution of Income", Economic Letters, vol. 13, pp. 207-211.

[148] Wilson R., 1968, "The Theory of Syndicates", Econometrica, vol. 36, pp. 119-132.

[149] Zamora B., 2009, "Does Female Participation Affect the Sharing Rule?", Journal of Population Economics (forthcoming). 